\title{
U.S. CONSUMERS' INTENTIONS TO USE WEARABLE TECHNOLOGY DEVICES IN THE CONTEXT OF HEALTHCARE
}

By

Ksenia Sergueeva

BSc, University of Toronto, 2010

BComm, Ryerson University, 2015

\author{
A thesis \\ presented to Ryerson University
}

in partial fulfillment of the

requirements for the degree of

Master of Science in Management (MScM)

in the program of

Master of Science in Management

Toronto, Ontario, Canada, 2017

CKsenia Sergueeva, 2017 


\begin{abstract}
AUTHOR'S DECLARATION
I hereby declare that I am the sole author of this thesis. This is a true copy of the thesis, including any required final revisions, as accepted by my examiners.

I authorize Ryerson University to lend this thesis to other institutions or individuals for the purpose of scholarly research.

I further authorize Ryerson University to reproduce this thesis by photocopying or by other means, in total or in part, at the request of other institutions or individuals for the purpose of scholarly research.

I understand that my thesis may be made electronically available to the public.
\end{abstract}




\title{
ABSTRACT \\ U.S. CONSUMERS' INTENTIONS TO USE WEARABLE TECHNOLOGY DEVICES IN THE CONTEXT OF HEALTHCARE
}

\author{
Ksenia Sergueeva, 2017 \\ Master of Science in Management (MScM) \\ Ryerson, University
}

As the adoption of wearable technology devices increases, so does the abandonment of these devices. Today, an increasing number of health-conscious consumers use wearable technology devices (WTDs) to self-track their health. Large tech companies are trying to close the gap between consumer wearables and their use in healthcare. This study provides an insight into consumer intentions to use wearable technology in healthcare. A quantitative study was conducted to examine factors that affect behavioural intent to use WTDs. The researcher surveyed 277 participants. The results from statistical analysis of the data gathered through survey methodology showed that the research model's constructs of performance expectancy, social influence, facilitating conditions, hedonic motivation, habit, and personalization were positively associated with the behavioral intention to use WTDs, while price value, privacy concerns, and health consciousness were not. The research findings contribute to the body of literature about consumer health information technology acceptance. Practitioners will also be able to use the results to increase the use of WTDs among consumers in the context of healthcare. Limitations of the study and recommendations for future research are discussed. 


\section{ACKNOWLEDGEMENTS}

I am extremely grateful to my supervisor, Dr. Norman Shaw, for his guidance, availability and patience in shepherding me through the journey of academic writing.

I am extremely grateful, too, to my co-supervisor and mentor Dr. Seung Hwan (Mark) Lee, for his critical support, encouragement, and guidance in master's career and future academic endeavors.

I am also grateful to my committee member Dr. Kimberly Bates for her support and advice in my academic career.

I appreciate the opportunity to work with many great professors at Ryerson University, including Dr. Hong Yu, Dr. Janice Rudkowski, Dr. Frances Gunn, and Dr. Donna Smith. I especially want to thank Dr. Hong Yu, without whose support through my undergraduate career this academic journey would have had a different path. I also want to thank my fellow students for a joyful learning experience.

Finally, thank you to my lovely mother, Lidia, who supported and encouraged me through these years, for her unconditional love, and her patience. You are my mother, my sister, my best friend and my biggest cheerleader! 


\section{TABLE OF CONTENTS}

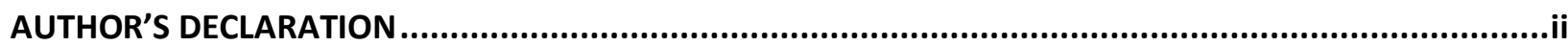

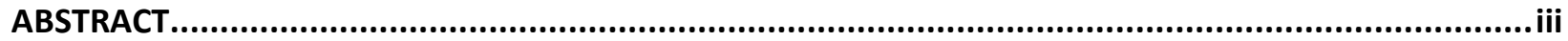

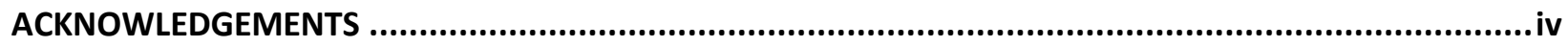

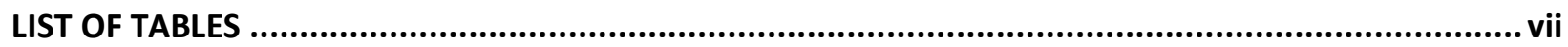

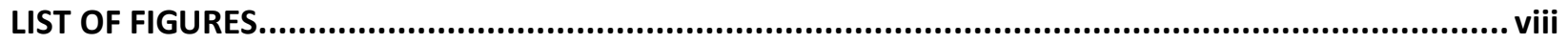

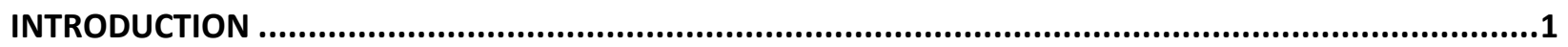

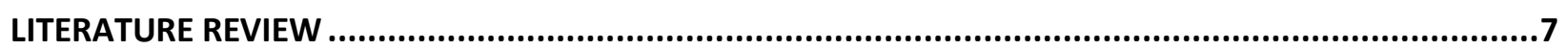

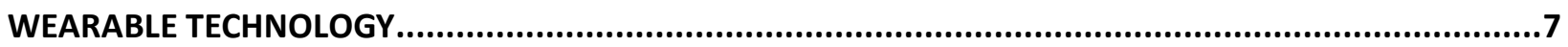

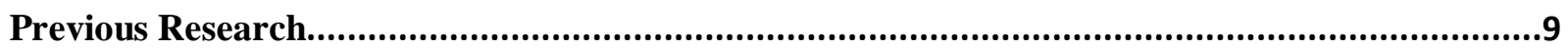

Unified Theory of Acceptance And Use Of Technology (UTAUT2) ..........................................11

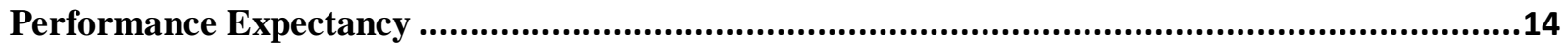

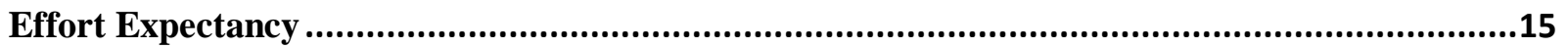

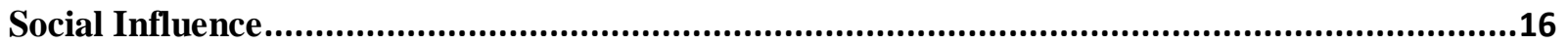

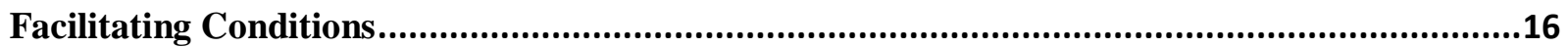

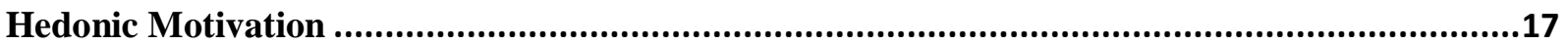

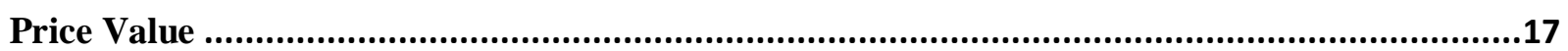

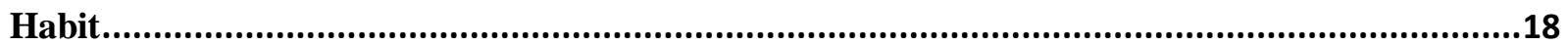

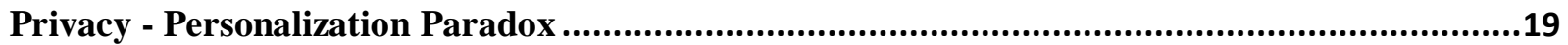

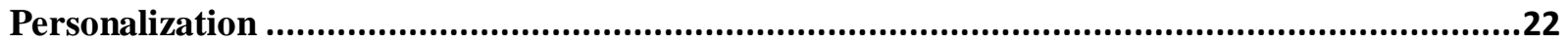

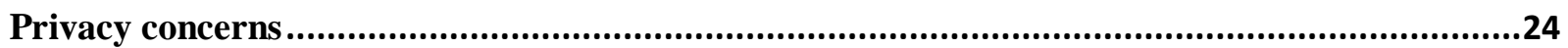

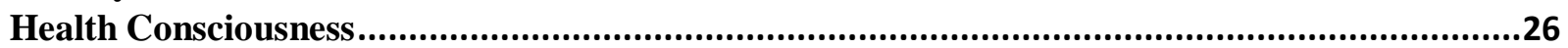

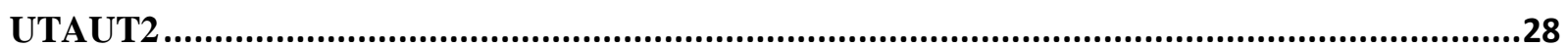

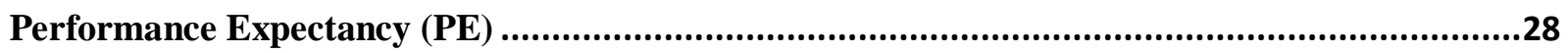

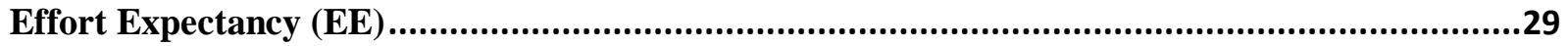

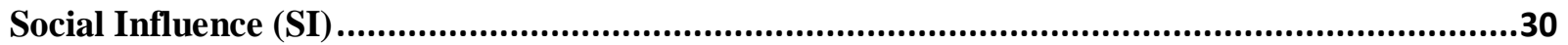

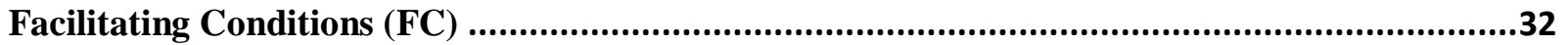

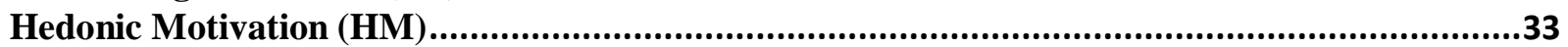

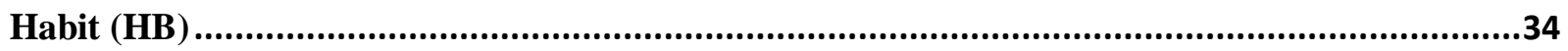

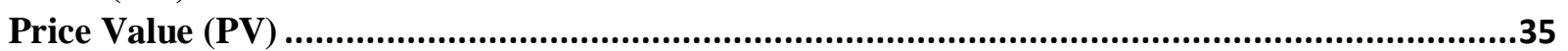

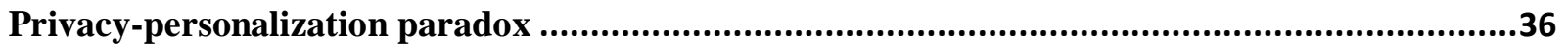

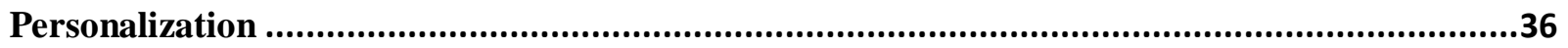

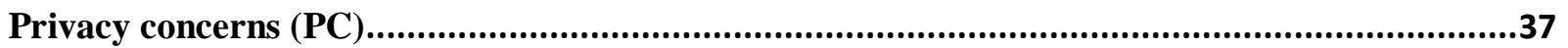

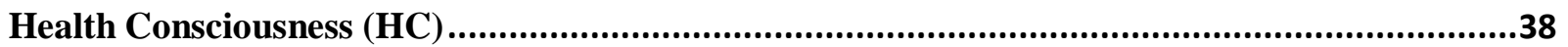

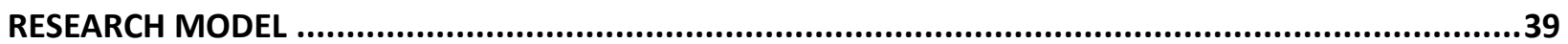

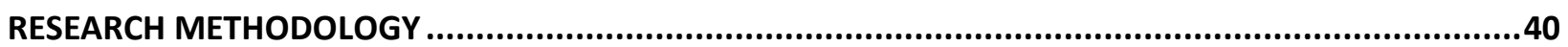

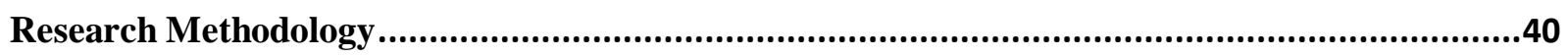

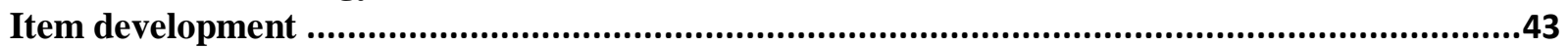

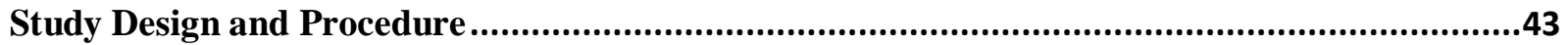

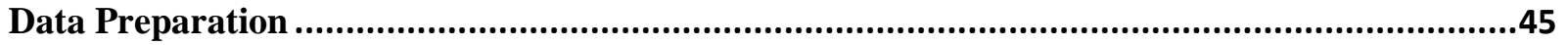

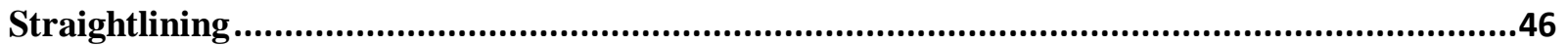

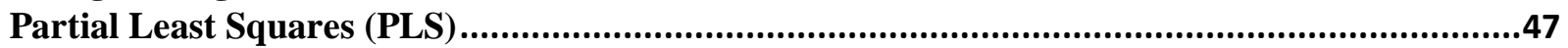




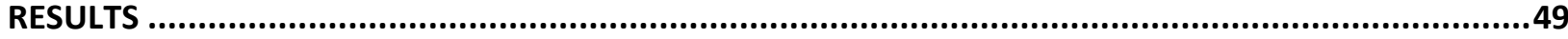

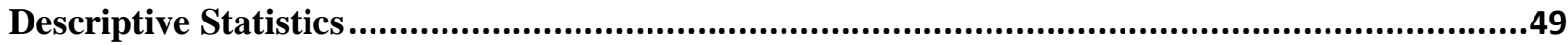

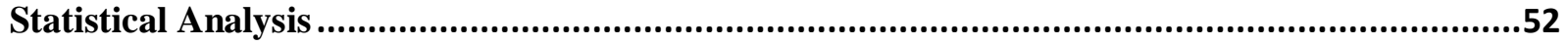

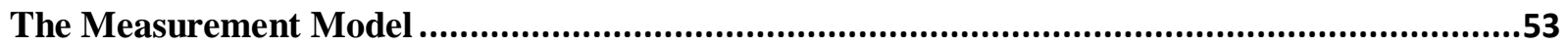

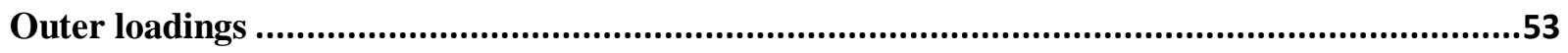

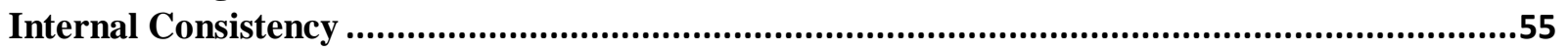

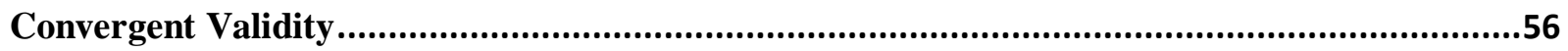

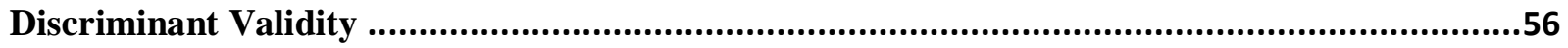

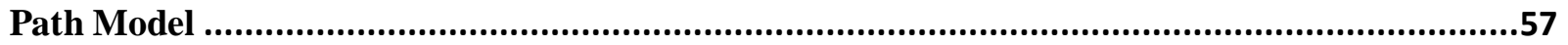

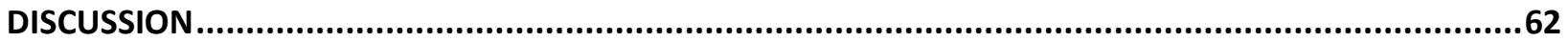

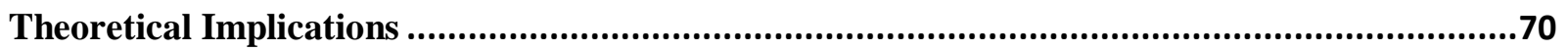

Implications for Practitioners ................................................................................................71

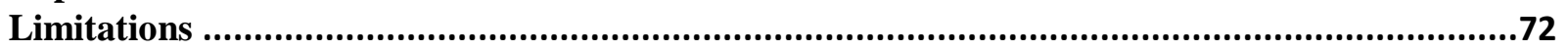

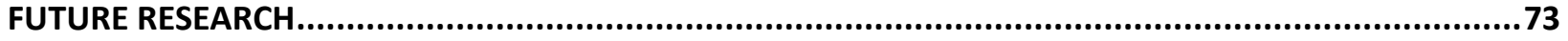

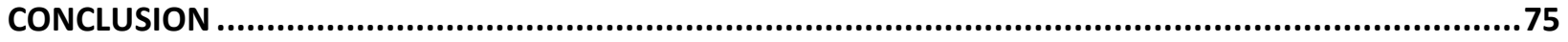

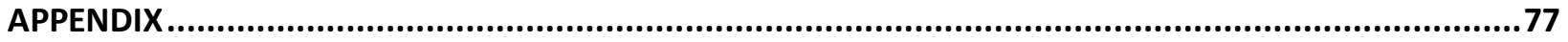

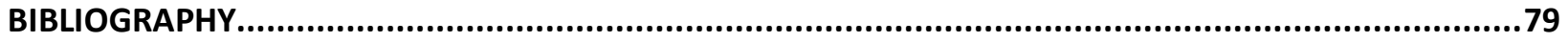




\section{LIST OF TABLES}

Table 1: Models and Theories........................................................................................ 12

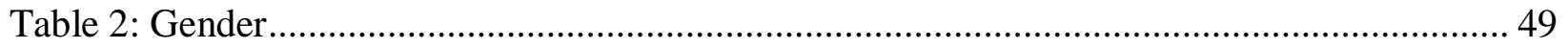

Table 3: Age Group by Generation..................................................................................... 50

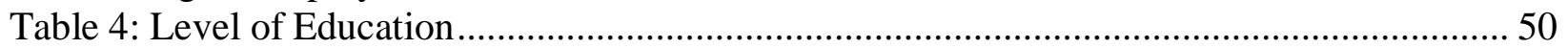

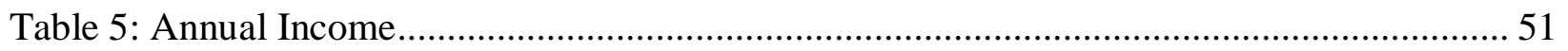

Table 6: Ownership of wearables ................................................................................... 51

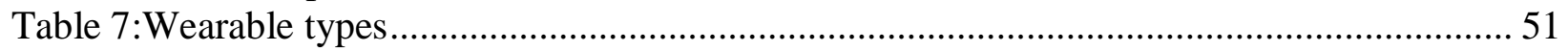

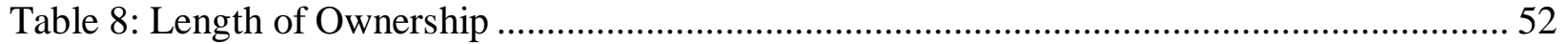

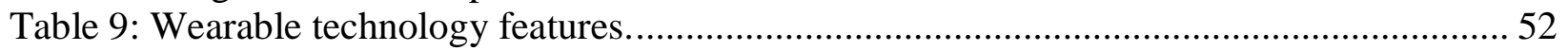

Table 10: Systematic Evaluation of PLS Results (Hair Jr et al., 2016) .................................... 53

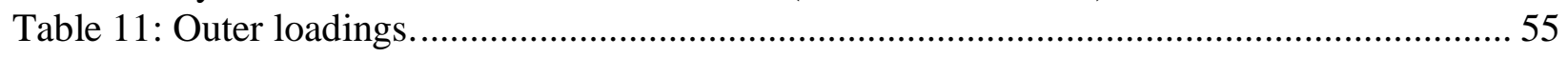

Table 12: PLS Quality Criteria. Construct reliability and Validity. ........................................56

Table 13: Table of Fornell-Larcker Scores. ........................................................................... 57

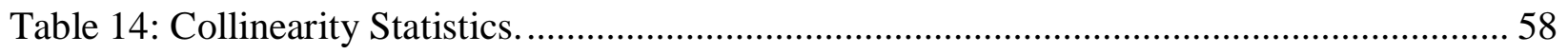

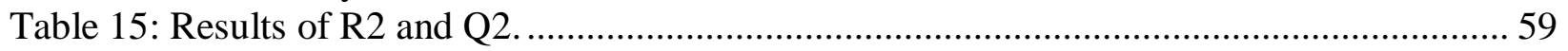

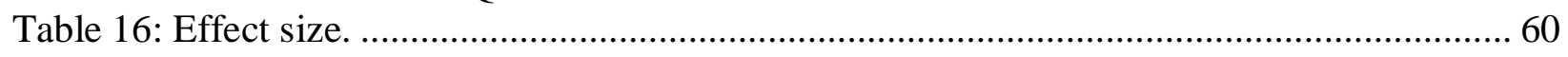

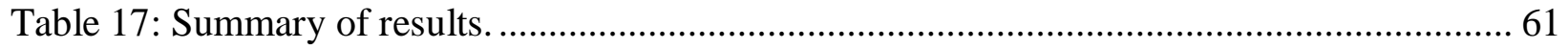




\section{LIST OF FIGURES}

Figure 1: UTAUT2 model (Venkatesh et al., 2012)....................................................... 14

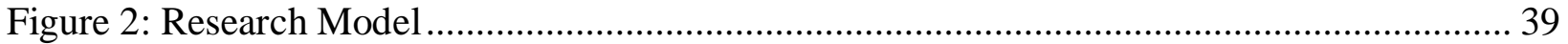




\section{INTRODUCTION}

Over the past several decades, rapid developments in technology have changed the way people monitor their health metrics through self-tracking (Abril, 2016). Self-tracking refers to self-quantification which involves an autonomous collection of health data about one-self via wearable technology devices (WTDs) (Choe, Lee, Lee, Pratt, \& Kientz, 2014; Pfeiffer, von Entress-Fuersteneck, Urbach, \& Buchwald, 2016). The data is then analyzed to produce statistical results that are read by the user or user's healthcare provider for further analysis. By 2019, it is estimated that the distribution of self-tracking wearable devices will exceed 126.1 million units and $80 \%$ will be wrist-worn wearables such as smartwatches and wristbands (IDC, 2015).

WTDs are defined as small electronic devices that consist of one or more sensors with computational capabilities that provide useful information and entertainment for the wearer (Salah, 2014). The sensors are embedded into the devices, which are attached to the parts of the body, such as the wrist or the head. Devices can also be embodied into clothing and jewelry. The purpose of this research is to investigate wrist worn wearable technology devices (WTDs) such as fitness trackers and smartwatches within the context of healthcare. From here and on in the document, I will refer to WTDs as wrist-worn wearable technology such as fitness trackers and smartwatches.

These devices are worn 24 hours a day in order to collect data continuously. The devices can be equipped with GPS systems, accelerometers, altimeters, pedometers and other monitors to record and calculate individuals' bodily movements, speed, locations and distance traveled. In addition, biometric sensors can measure bodily functions such as heart rate, sweat levels, sleep quality, sleep quantity and respiration. WTDs work together with smartphone applications to 
record, store and analyze personal health, fitness and lifestyle data. For output, WTDs can show information in a variety of ways, from the flashing of LED lights on a wrist device to a complex display of data on a mobile app. These devices allow users to create detailed records of their physical activities, and to plan future health and fitness oriented goals. Consumer studies have found that one in six consumers currently uses WTDs on a daily basis (Nielsen, 2014a). Some of the more dominant players in wearable technology are Fitbit, Jawbone, Misfit, Garmin, Sony, Samsung, LG, Motorola, and one of the more successful, Apple. A survey from Accenture shows that the number of consumers that use WTDs to monitor their health has doubled since 2013 (Accenture, 2015). Emerging trends in personal health care and the increasing interest of quantifying personal health by consumers and by professional healthcare providers are seen as the drivers of WTD adoption (Ledger, 2014). Many professional health related providers see an opportunity to facilitate services related to research and healthcare when the collection of health data is easily made available by WTDs. Shul et al. (2014) argue that just the act of monitoring behaviour can have strong motivational effects that stimulate healthy actions. BCC Research predicted that the wearable computing market will reach more than $\$ 171.2$ billion in 2021 (BCC Research, 2016) and WTDs are expected to play a transformative role in fitness, health, and other medical applications (Salah, 2014). Receiving health advice from artificial intelligence on a smartwatch or a wristband will no longer be too far-fetched (NPR, 2015).

Today, tech companies like Google, Apple and Samsung are linking WTDs to healthcare with bridging applications. Technology experts forecast that future technological products will serve consumers and professional markets (BusinessInsider, 2016). Apple recently launched ResearchKit, which is an open-software platform to create health apps. It uses WTDs for medical research. They also launched CareKit, which is an open-software platform to create 
health apps that help people manage various medical conditions and share that information with their physicians (Apple). Among the first four apps that were released by Apple were those that help manage diabetes and track symptoms of depression (CBCnews, 2016). This is Apple's step to accelerate integration of WTDs into healthcare.

Apple has designed a platform for health apps that could help consumers manage their medications, connect with their doctors virtually, and help physicians reach new patients. They are available on iTunes via HealthTap (HealthTap, 2017). These WTD apps let patients know when they are about to run out of medication, and then they can order medication by a simple tap on their wrist. Doctors that use WTDs can receive alerts when a patient has arrived at their office or the hospital, and then be able to attend them more efficiently with the right electronic health record. WTDs can also help medical staff communicate among each other efficiently about patient cases. It is expected that other wearable manufactures will follow this approach, thereby making it easier for medical researchers and doctors to collect data and resolve issues regarding the reliability and the safety of WTDs. They will also be able to improve communication between patients and doctors (NPR, 2015). A survey from Accenture revealed that most WTD consumers use them to track fitness, nutrition, and their diet, but the devices could provide a broader usage. For example, participants of the survey preferred virtual doctor appointments rather than personal ones (Accenture, 2015).

According to the Food and Drug Administration (FDA), patients and consumers use digital health to better manage and track their health. The use of WTDs in the context of digital health helps to reduce inefficiencies, improve access, reduce costs, increase quality of health care and make medicine more personalized for patients. Use of WTDs, together with other devices such as smartphones, connects users via social networks to provide innovative ways to monitor 
health and wellbeing, which, in turn, improves healthcare and health outcomes (FDA, 2017). However, integration of this ground-breaking technology into healthcare begins from understanding consumer acceptance and use of WTDs.

While the adoption rate has increased, the abandonment rate is still high (Piwek, Ellis, Andrews, \& Joinson, 2016). Researches and practitioners may be able to reduce the abandonment rate of these devices by further investigating the acceptance and use of WTDs. There are several issues with the acceptance and use of WTDs. For example, some consumers fail to recognize the potential health benefits of WTDs beyond the counting of steps and the calories burned (L. H. Wu, Wu, \& Chang, 2016). Many new improvements in WTDs that allow for a real-time view of personalized data by health care providers, such as the hands-free data collection of measurements for heart rate, blood flow and blood oxygen, are still widely unknown to consumers (Salah, 2014). Additionally, consumer surveys show that more than 50\% of WTD owners abandon their devices after only one year or less of using the technology (Ledger, 2014). According to another research conducted by PwC (2014) only half of those who own the technology wear them on a daily basis $(\mathrm{n}=1000)$.

Practitioners need to not only attract, but also to motivate consumers to continue using their WTDs. In order to provide customized feedback, WTDs collect health data by implicitly monitoring individuals' behaviours and vital signs. According to Park (2014), personalization increases adoption and continued use of an IT innovation. Extant studies of WTDs have determined that feedback, information display, and specific design principles all play a role in keeping the user engaged with the technology (Wu, Sum, \& Nathan-Roberts, 2016). This suggests that personalization could have an impact on behavioural intention to use WTDs. 
Furthermore, implementing wearables in hospitals and clinics requires manufacturers and companies to not only address regulatory and security requirements (Accenture, 2015; FDA, 2017) but also technical, operational and social factors that influence consumer behaviour (Venkatesh, Thong, \& Xu, 2012). The FDA requires manufacturers and companies to address the relevant regulations and security issues, and incorporate the privacy concerns of consumers in the context of WTDs. As personalized feedback is a key component of WTDs and their services, it requires consumers to disclose personal health information, which raises privacy concerns in users. Previous studies have addressed issues of privacy risks and privacy concerns (Gao, Li, \& Luo, 2015; Li, Wu, Gao, \& Shi, 2016; L. H. Wu et al., 2016) and found privacy to be a significant factor in influencing behavioural intent. This research extends the findings of Guo et al. (2015) by investigating the impact of personalization, privacy concerns, and health behaviour on behavioural intent to use WTDs in the context of healthcare.

In addition, previous research studied the adoption of WTDs when the technology was in its infant stage. Today, the technology is more widely adopted and therefore it is important to add Habit and Price Value as factors that may influence behavioural intention. This is a quantitative deductive study. The purpose of this thesis is to add to the body of knowledge by identifying the factors that affect behavioural intention to use wearable technology devices (WTDs). Consequently, there are three research questions:

1) What factors facilitate individuals to change their behavioural intention to use wearable technology devices?

2) Are consumers reluctant to share personal data collected on their WTDs, even when it provides greater personalization?

3) Does health consciousness in consumers facilitate intention to use wearable technology devices? 
The remainder of this paper is organized as follows. The next section is the review of the literature, which includes our development of the hypotheses and concludes with the research model. The third section of this paper describes the methodology. The results are then discussed, followed by the conclusion that includes implications for the practitioners, limitations and suggestions for future studies. 


\section{LITERATURE REVIEW}

In this section, wearable technology is explained, followed by the development of our hypotheses, supported by relevant literature. The literature review includes extant studies that investigated user's acceptance of wearable technology devices (WTDs) in healthcare. In order to investigate consumer perceptions on self-tracking technology, the unified theory of acceptance and use of technology (UTAUT2) has been selected as the foundational framework. It is extended with the construct of health consciousness and the constructs from the personalizationprivacy paradox.

\section{WEARABLE TECHNOLOGY}

The digital evolution of technology has allowed our lives to be digitized. Today people digitally measure and record their every day activities, such as exercise, habit and moods with wearable technology devices (WTDs). Cultural obsession with digitally recording of health measurements has facilitated an increase of WTD adoption (Fang \& Chang, 2016). WTDs are small electronic devices with sensors and computational capabilities (Salah, 2014). These devices can be attached to the user's body, such as wrists or head, or to their clothes. WTDs are fully functional and self-contained allowing users to access information anywhere and anytime (Tehrani, 2014). Fitness bracelets and smartwatches are the two most popular wearable technology devices that are used to monitor health and fitness activities (Gao et al., 2015; Piwek et al., 2016). In this research, wrist-worn health and fitness trafficking devices are referred to as wearable technology devices (WTDs). This type of consumer technology is used to track health and physical activities, such as exercise duration, sleep patterns, calories burned and steps counted (Lewy, 2015). In addition to location based services that track users, the new type of 
WTDs are capable of measuring stress levels with an ectodermal sensor (i.e., a skin sensor) (Mozos et al., 2017). A woman's ovulation period, can be tracked via her body temperature, indicating when she is most fertile (Lewandowski, Chao, \& Niżański, 2016). Based on the recorded health metrics by the sensors, WTDs can provide "personalized, immediate, and goaloriented feedback" (Piwek et al., 2016). Smartwatches (e.g., Apple watch, Samsung Galaxy and Pebble Steele) appeal to a broad audience because they are considered as multi-functional technology: not only do they track health and physical activities, but they also have other functions of "smart" devices that allow location tracking and communication between users (Sultan, 2015). It is forecasted that sales of smartwatches will reach 141 million units by 2018 (Statista, n.d.).

There is a growing population of WTD users who are interested in personal analytics as a concept of self-discovery, a movement called the "Quantified - Self" (QS) (Swan, 2009). The term QS began in 2007, when Wolf and Kevin Kelly, editors of Wired, started the Quantified Self blog (Quantified-Self, 2017). The blog was to teach health enthusiasts about how to quantify health and apply data analysis to all things that may be measured about the human body and mind. In order to improve health, the followers of this philosophy use WTDs to track data about broad aspects of their daily life, which includes any kind of biological, physical, emotional, or environmental information that can be operationalized and quantified (Prince, 2014). Devices may track their mood, any type of physical activity, food consumed, blood pressure, weight, etc. The QS movement argues that self-tracking increases patient involvement in healthcare because self-care empowers patients (Van den Bulck, 2015).

Since the commercialization of WTDs is increasingly successful, it is important to investigate and build on previous research with regards to the acceptance and use of technology 
theories in the context of WTDs. This study empirically tests a research model that hypothesizes the factors that influence the use of WTDs by North American Consumers.

The next section examines previous research and explains the theoretical framework chosen for this research.

\section{Previous Research}

Although many studies have employed technology adoption theories to investigate new technologies, there are only a limited number of studies that have investigated consumers' acceptance and use of WTDs. A summary of previous research on WTDs is presented in this section.

In a study by Kim and Shin (2015), researchers used TAM and identified that subcultural appeal and costs of the device were notable antecedents of user attitudes and intention to use WTDs. Wang et al. (2016) also used TAM as their theoretical foundation and found that perceived usefulness is one of the significant variables that directly influences consumers' behavioural intention and attitude towards the technology acceptance of WTDs.

In another study, Yang et al. (2016) identified that perceived usefulness, social image and enjoyment influenced the perceived benefits of consumers and ultimately their behavioural intention to adopt WTDs. Furthermore, in a qualitative study, Canhoto \& Arp (2016) found that consumer attitudes towards health and fitness, performance expectancy and social influence positively affect adoption and sustained use of wearables among consumers.

In one of the most recent studies, Wu, Wu \& Chang (2016) explored intentions to use a smartwatch from the consumer's point of view by combining three theories: Innovation 
Diffusion theory (IDT), TAM and UTAUT. Researchers identified that among the constructs tested, relative advantage, result demonstrability, enjoyment, social influence and attitude have significant impact on behavioural intention to use smart watches. Wu, Wu, \& Chang (2016), identified that effort expectancy was not significant on intention to use. Liu \& Gao (2016) found that trust and social benefit can positively influence purchase intention of WTDs, while familiarity fails to influence trust and intention to purchase.

A study by Gu et al., (2016) used UTAUT2 as a theoretical framework and identified that performance expectancy, hedonic motivation and facilitating condition impact the initial trust of consumers, while privacy concerns have a negative impact on behavioural intention to adopt WTDs. The study also determined that effort expectancy did not have a significant effect on behavioural intention to adopt WTDs. Gao et al., (2015) showed that consumers who use healthcare WTDs are influenced by performance expectancy, effort expectancy, hedonic motivation, functionality, social influence, perceived privacy risks and perceived vulnerability, self - efficacy, and perceived severity.

UTAUT2 has previously been applied to the adoption of health information technologies (HIT). The studies have validated the model for technology adoption intention. Examples include: the introduction of telemedicine (P. F. Wu, 2012), the adoption of HIT in clinics in Thailand (Kijsanayotin, Pannarunothai, \& Speedie, 2009), the use of electronic medical records (Trimmer, Cellucci, Wiggins, \& Woodhouse, 2009), and healthcare wearable devices (Gao et al., 2015; Gu et al., 2016). UTAUT2 (Gao et al., 2015; Gu et al., 2016; Morosan \& DeFranco, 2016; Oechslein, Fleischmann, \& Hess, 2014; Slade, Williams, \& Dwivedi, 2014; Venkatesh et al., 2012) is considered as an enhanced model, that is parsimonious with robust characteristics, that could better predict factors that influence individual's intention and usage of technology. 
However, it remains unknown to what extent the addition of health behaviour and privacy-related factors to adoption theory will enhance its predictive capability for WTDs use in the context of U.S. consumer.

\section{Unified Theory of Acceptance And Use Of Technology (UTAUT2)}

With the evolution of information technology, there have been multiple models that have been proposed to explain the adoption and usage of technology by individuals and/or organizations (Compeau, Higgins, \& Huff, 1999; Venkatesh, Morris, Davis, \& Davis, 2003). Venkatesh et al. (2003) unified existing acceptance models in order to provide researchers with an updated, all-inclusive user acceptance model known as the Unified Theory of Acceptance and Use of Technology (UTAUT).

UTAUT was developed from eight major user acceptance models: the Innovation Diffusion Theory (IDC) (Rogers, 1962), Theory of Reasoned Action (TRA) (Fishbein \& Ajzen, 1976), the Theory of Planed Behaviour (Ajzen, 1991), Social Cognitive Theory (SCT) (Bandura, 1977);(Compeau \& Higgins, 1995), Model of PC Utilization (MPCU) (Thompson, Higgins, \& Howell, 1991), Motivation Model (MM) (Davis, Bagozzi, \& Warshaw, 1992), a combination of the TPB/TAM (C-TPB-TAM)(Taylor \& Todd, 1995b), and the Technology Acceptance Model (TAM) (Davis, 1989), and TAM2 (Venkatesh \& Morris, 2000). See Table 1 for more details regarding the models. Seven constructs from the eight models explained intention to use a new technology, but only four key constructs have direct and significant roles on both behavioural intention (BI) and actual use: performance expectancy (PE), effort expectancy (EE), social influence (SI) and facilitating conditions (FC). Venkatesh et al. (2003) also added age, gender, and experience as moderating factors. 


\begin{tabular}{|c|c|c|c|}
\hline $\begin{array}{l}\text { Author } \\
\text { and year }\end{array}$ & $\begin{array}{l}\text { Models and } \\
\text { Theories } \\
\end{array}$ & Definition & Core Constructs \\
\hline $\begin{array}{l}\text { Rogers } \\
(1962)\end{array}$ & $\begin{array}{l}\text { Innovation } \\
\text { Diffusion Theory } \\
\text { (IDT) }\end{array}$ & $\begin{array}{l}\text { Theory is grounded in sociology and has been used since } \\
\text { 1960s to study different innovation tools, from agricultural } \\
\text { to organizational. The study focuses on understanding } \\
\text { how, why and the rate that innovative ideas and } \\
\text { technology spread in a social setting. Rogers (1995) has } \\
\text { revamped the theory and changed direction from focusing } \\
\text { on persuading individuals to change, to the evaluation of } \\
\text { products and behaviors so they become better fits for the } \\
\text { needs of individuals. }\end{array}$ & $\begin{array}{l}\text { Relative } \\
\text { Advantage, } \\
\text { Ease of use, } \\
\text { Complexity, } \\
\text { Observability, } \\
\text { Trialability, } \\
\text { Image, } \\
\text { Voluntariness Of } \\
\text { Use }\end{array}$ \\
\hline $\begin{array}{l}\text { Fishbein \& } \\
\text { Ajzen } \\
(1975)\end{array}$ & $\begin{array}{l}\text { Theory of Reasoned } \\
\text { Action (TRA) to } \\
\text { measure } \\
\text { performance and } \\
\text { behaviour intention. }\end{array}$ & $\begin{array}{l}\text { TRA is a theory drawn from social psychology and } \\
\text { considered to be one of the most fundamental and } \\
\text { influential theories of predicting a wide range of human } \\
\text { behaviour (Sheppard et al. 1988). }\end{array}$ & $\begin{array}{l}\text { Attitude } \\
\text { Subjective Norm }\end{array}$ \\
\hline $\begin{array}{l}\text { Bandura } \\
(1986)\end{array}$ & $\begin{array}{l}\text { Social Cognitive } \\
\text { Theory (SCT) to } \\
\text { determine usage of } \\
\text { information systems }\end{array}$ & $\begin{array}{l}\text { SCT relates to learning from observing other people's } \\
\text { behaviour. SCT includes motivational and self-regulatory } \\
\text { mechanisms, through reinforcing consequences. }\end{array}$ & $\begin{array}{l}\text { Outcome } \\
\text { expectations - } \\
\text { performance, } \\
\text { Outcome } \\
\text { expectations - } \\
\text { personal, } \\
\text { Self-efficacy, } \\
\text { Affect, } \\
\text { Anxiety }\end{array}$ \\
\hline $\begin{array}{l}\text { Thompson } \\
\text { et al (1991) }\end{array}$ & $\begin{array}{l}\text { Model of PC } \\
\text { Utilization (MPCU) } \\
\text { to determine } \\
\text { behaviour of PC } \\
\text { usage }\end{array}$ & $\begin{array}{l}\text { Derived from Triandis' (1977) theory of human behaviour } \\
\text { with opposite perspectives than those defined in TRA \& } \\
\text { TPB. Thompson et al (1991) redefined the theory for IS } \\
\text { context and used the new model to predict PC utilization. } \\
\text { MPCU predicts individual acceptance and use of } \\
\text { information technology. It focuses on usage behaviour } \\
\text { rather than behavioural intention. }\end{array}$ & $\begin{array}{l}\text { Social Factors, } \\
\text { Affect towards use, } \\
\text { Long Term, } \\
\text { Consequences, } \\
\text { Facilitating } \\
\text { Conditions, } \\
\text { Complexity }\end{array}$ \\
\hline $\begin{array}{l}\text { Davis et al } \\
\text { (1992) }\end{array}$ & $\begin{array}{l}\text { Motivational Model } \\
(\mathrm{MM}) \text { to describe } \\
\text { behaviour of } \\
\text { technology adoption } \\
\text { and use }\end{array}$ & $\begin{array}{l}\text { MM is used in psychology to explain behaviour. Davis et } \\
\text { al. (1992) applied MM theory to understand adoption and } \\
\text { use of new technology. }\end{array}$ & $\begin{array}{l}\text { Motivation } \\
\text { (Extrinsic and } \\
\text { Intrinsic) }\end{array}$ \\
\hline $\begin{array}{l}\text { Taylor \& } \\
\text { Todd } \\
(1995)\end{array}$ & $\begin{array}{l}\text { Combination of } \\
\text { TAM \& TPB }\end{array}$ & $\begin{array}{l}\text { TPB is a theory which has been extended from TRA by } \\
\text { the addition of perceived behaviour control constructs. } \\
\text { TPB has been applied to the understanding of user } \\
\text { acceptance and usage of many different technologies } \\
\text { (Venkatesh et al., 2003),(Taylor \& Todd, 1995a). }\end{array}$ & $\begin{array}{l}\text { Perceived } \\
\text { Usefulness, } \\
\text { Perceived Ease Of } \\
\text { Use, } \\
\text { Attitude, } \\
\text { Subjective Norm, } \\
\text { Perceived } \\
\text { Behavioural, } \\
\text { Control }\end{array}$ \\
\hline $\begin{array}{l}\text { Venkatesh } \\
\text { \& Davis } \\
(2000)\end{array}$ & $\begin{array}{l}\text { Technology } \\
\text { Acceptance Model } \\
2 \text { (TAM2) an } \\
\text { extension of TAM }\end{array}$ & $\begin{array}{l}\text { TAM is a theory that has been designed and tailored to } \\
\text { information technology context to predict IT acceptance } \\
\text { and usage in a workplace (Davis, 1989). When TAM was } \\
\text { first proposed, the dependent variable was "intention to } \\
\text { use" and not "actual use", hence it seeks to explain } \\
\text { intention of the behaviour rather than the outcome. } \\
\text { Venkatesh and Davis (2000) have extended TAM into } \\
\text { TAM-2 by including subjective norm as an additional } \\
\text { predictor of intention in behaviour, which was borrowed } \\
\text { from TRA. }\end{array}$ & $\begin{array}{l}\text { Perceived } \\
\text { Usefulness, } \\
\text { Perceived Ease of } \\
\text { Use, } \\
\text { Subjective Norm, } \\
\text { Experience, } \\
\text { Voluntariness, } \\
\text { Image, } \\
\text { Job Relevance, } \\
\text { Output Quality, } \\
\text { Result } \\
\text { Demonstrability }\end{array}$ \\
\hline
\end{tabular}

Table 1: Models and Theories 
After its development, UTAUT served as a research framework for a variety of studies in different disciplines and technologies. According to Lewis, Fretwell, Ryan and Parham (2013), UTAUT was a baseline which has been applied to research in many organizations in different fields. From a number of empirical tests of UTAUT, the theory explained approximately $70 \%$ of the variance in behavioural intention and 50\% in actual use of the technology (Holden \& Karsh, 2010).

After systematic inquiry, Venkatesh et al. (2012) expanded upon UTAUT to pay specific attention to the consumer use context and they developed the Unified Theory of Acceptance and Use of Technology 2 model (UTAUT2). UTAUT only included extrinsic motivation which focused on the functionality and utility of the IT and IS. When considering the voluntary nature of consumer adoption, Venkatesh et al. (2012) included intrinsic motivation in UTAUT2, keeping the original four constructs that are concerned with extrinsic motivation and adding three constructs that are concerned with intrinsic motivation (Vallerand, 1997). The three constructs are: Hedonic Motivation, Price Value and Habit. By adding the new constructs, UTAUT2 increased the variance explained of behavioural intention by $18 \%$ and the use of technology by $12 \%$ (Venkatesh et al., 2012). See Figure 1 for a full model of UTAUT2.

The next section will discuss all seven constructs of UTAUT2 in greater detail. 


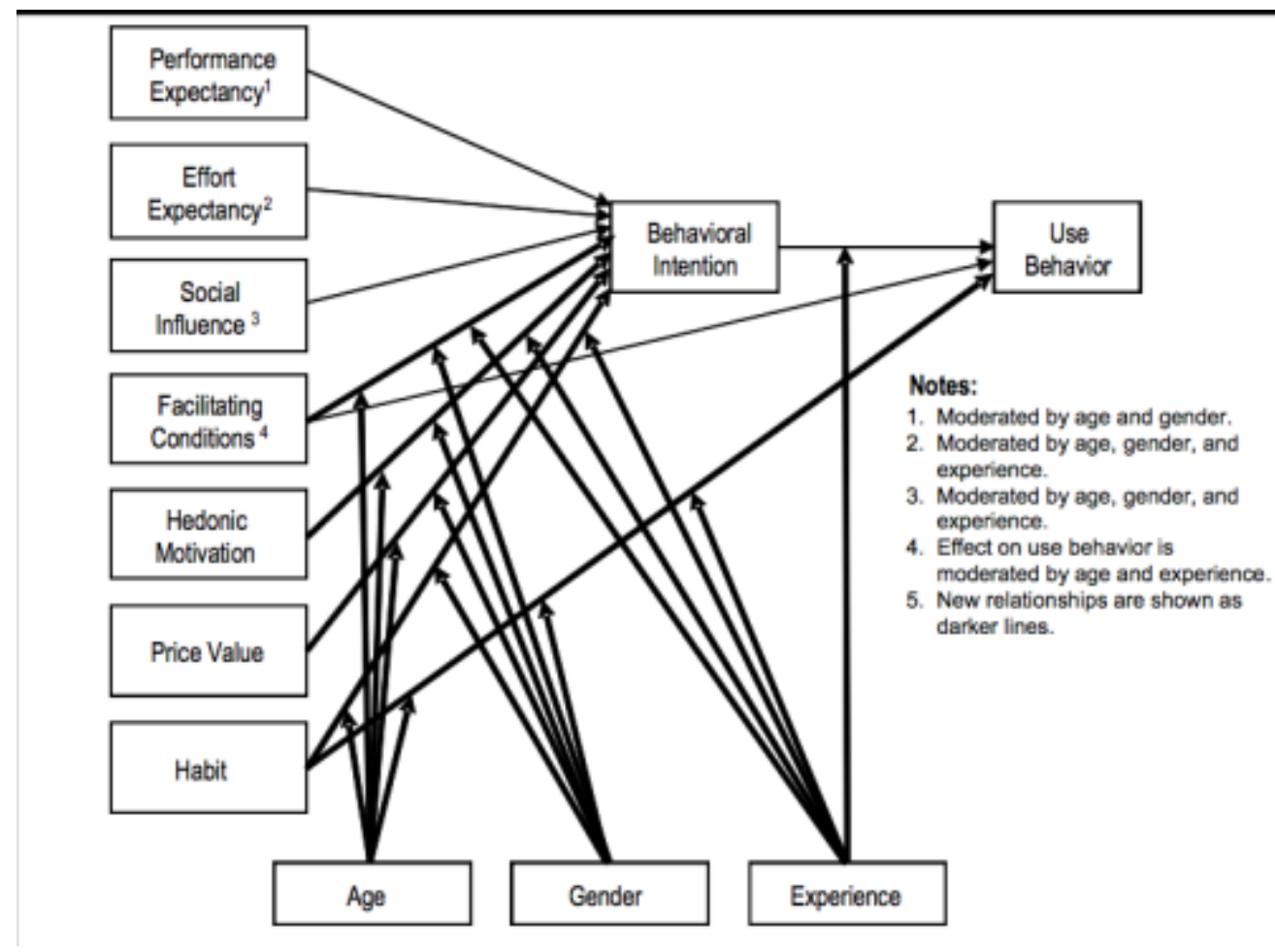

Figure 1: UTAUT2 model (Venkatesh et al., 2012).

\section{Performance Expectancy}

Performance expectancy is defined as "the degree to which an individual believes that using the system will help him or her attain gains in job performance" (Venkatesh et al., 2003, p. 447 \#914). PE is one of the important factors when deciding to use a technological innovation (S. A. Brown \& Venkatesh, 2005). Several empirical studies identified this construct to have the largest effect on intention to use (ITU) (Baptista \& Oliveira, 2015). This construct is derived from five different models that relate performance expectancy to "perceived usefulness" in TAM, extrinsic motivation in MM, "job fit" in MPCU, "relative advantage" in IDT, and "outcome expectations" in SCT (Venkatesh et al., 2003). The meta-analysis by King and He (2006, p. 751) concluded that the influence of performance expectancy was the most significant factor in the adoption of technology. An individual's opinion of the effectiveness of using a 
technology is described by this construct (Venkatesh et al., 2003). Users must feel confident that the technology is reliable and that it will function for the purpose that it was designed. In terms of consumers' intention to use, consumers expect that WTDs will provide a positive benefit. For example, the device can effectively help consumers monitor their health, by recording their daily physical activity, physical conditions, and vital signs, enabling them to make personal healthcare plans. In the context of this study, when a consumer identifies his or her health needs, the WTD's functionality becomes important in order to effectively and efficiently fulfill those needs.

\section{Effort Expectancy}

Effort expectancy is defined as the "degree of ease associated with the use of the system or technology" (Venkatesh et al., 2003, p. 450). Previous research suggests that it is significant only during the first-time use period, as it becomes insignificant over the extended use of the technology (Anderson, Schwager, \& Kerns, 2006; Venkatesh \& Zhang, 2010). In the context of WTDs, effort expectancy is used to measure a consumer's perceived ease of using the technology. In other words, if the effort involved in spending time learning and using the technology is low, the user is more likely to use the technology. In the context of this study, operating this technology requires users to continuously wear the technology linked to a smartphone. Today, there are approximately 222.9 million smartphone users in United States (Statista, 2017). According to an IDC study, $79 \%$ of smartphone users have their devices on them at all times (IDC, 2014). Hence, wearing the WTD on the wrist continuously should be easy because the device requires a smartphone, which the user already carries. Learning to use a new device that is connected with the existing technology should not be difficult for experienced users. 


\section{Social Influence}

The direct relationship of social influence on an individual's behavioural intent was hypothesized and proved in UTAUT2 (Venkatesh et al., 2012). Social Influence is defined as the "degree to which an individual perceives that important others believe he or she should use the new system" (Venkatesh et al., 2003, p. 451). It is a direct determinant of behavioural intention, which is represented as subjective norm in previous theories such as TRA, TAM2, TPB/DTB and C-TAM-TPB. Social influence refers to the extent that consumer behaviour is influenced by others. For instance, family and friends have been shown to influence the adoption of mobile payments (Shaw, 2015) and mobile commerce (Chen, Zhang, \& Zhao, 2015).

Some previous studies have suggested that social influence is a stronger indicator than a consumer's satisfaction with technology performance (Oliver, 1999), meaning that a consumer's intention to use the technology is influenced more by social influence than the performance of the technology. Previous empirical studies of adoption HIT have concluded that social influence positively affects behavioural intention to adopt different kinds of HIT, such as mobile health services (Sun, Wang, Guo, \& Peng, 2013) and healthcare wearable devices (Gao et al., 2015).

\section{Facilitating Conditions}

Facilitating conditions have been defined by Venkatesh et al. (2003) as the belief of an individual that the system is supported by an organizational and technical infrastructure. Findings from an empirical study by Venkatesh et al. (2003) suggest that facilitating conditions have a direct influence on usage beyond that explained by behavioural intentions. In fact, experienced users of technology seek multiple ways to find help and support throughout the duration of their use of the technology. For example, when consumers find that their WTD does not function properly, they find a way to contact the manufacturer via online or telephone, or 
they go to the retail store where the device was purchased. Also, consumers need to be certain that if there is a problem with understanding the output, they can contact their healthcare provider or the manufacturer in various ways (e.g., phone, online, in person). Therefore, FC is an important factor in the adoption of technology (Lai, 2015). Several studies have supported that FC have a positive impact on behavioural intention in technology adoption (Agarwal \& Karahanna, 2000; Canhoto \& Arp, 2016; Gu et al., 2016).

\section{Hedonic Motivation}

In previous consumer behaviour research, hedonic motivation from motivation theory has been included as a key predictor in the context of consumer technology use (S. A. Brown \& Venkatesh, 2005). Hedonic motivation is defined as the fun or pleasure that is derived from using a technology (Venkatesh et al., 2012). The construct is shown to be an important influencing factor of technology acceptance and use in IS research (Venkatesh et al., 2012). Previous research found the construct to have a positive effect on consumer behavioural intention to use wearable devices (Gao et al., 2015; Gu et al., 2016). Unique characteristics of WTDs, such as flashing LED lights which give notification of real-time achievements, or statistical graphs which give detailed feedback of attained goals, bring consumers pleasure and enjoyment while they monitor their daily activities. For example, recent gamification of wearable devices, where consumers compete against each other in the number of steps a day they take, makes the use of WTDs more enjoyable and more likely to contribute to a consumer's continuous use. Similarly comparing results with others in the general population is a positive hedonic motivation.

\section{Price Value}

Price value is referred to as "consumers' cognitive tradeoff between the perceived 
benefits of the application and the monetary cost for using them" (Venkatesh et al., 2012, p. 161). In the context of consumer technology use, price could play an important factor in behavioural intention to use. Consumers incur costs associated with the purchase and use of the technology, unlike workplace technologies, where the company incurs all the cost associated with technology (Venkatesh et al., 2012). Most of the consumer behaviour research has included constructs related to cost to explain consumers' actions (Dodds, Monroe, \& Grewal, 1991).

When a consumer perceives that the benefits of using a technology outweigh the monetary cost, the price value has a positive impact on intention to use the technology device (Venkatesh et al., 2012). In other words, if consumers identify that by spending more money on a purchase of a new technology they would receive positive benefits (e.g., From the functions of the WTD), the monetary value would not matter. In the past, studies that have used UTAUT2 included price value and suggested that the construct is a significant factor that affects behavioural intention in consumers (Alwahaishi \& Snásel, 2013; Arenas-Gaitan \& Peral-Peral, 2015; S. Yang, 2013). In the context of WTDs where the technology is considered to be relatively expensive (price ranges from $\$ 200$ to $\$ 500$ + Canadian dollars), consumers will be willing to pay a higher price if they perceive a significant health benefit. Potential users would analyze all attributes of WTD functionality when they are making the decision to purchase. The price value is positive when the benefits of using the WTDs are perceived to be greater than the cost, and such cases price value would have a positive effect on behavioural intention.

\section{Habit}

Habit reflects the extent to which consumers' tend to perform automatic behaviour due to previous learning (Venkatesh et al., 2012), specifically after some degree of repetition. Habit has been validated as a predictor of behaviour intention (Pavlou \& Fygenson, 2006), and more 
recently as a predictor of continuous use of information system (Lankton, Wilson, \& Mao, 2010). Habit may result from the repetitive use of WTDs in the context that consumers use them together with other smart devices, such as smart phones or iPads. Thus, a repetitive use of one device, may facilitate the transfer of behaviour to another, facilitating repetitive use. Previous studies of WTDs that had UTAUT2 as a theoretical foundation to determine consumers' behavioural intention to use WTDs, excluded habit as a construct because the technology was still in its infant stage (Gao et al., 2015; Gu et al., 2016). Now as the technology has become increasingly popular, it is important to include this construct in the study of WTDs.

WTDs also gave rise to a new trend of "quantified self” where consumers use WTDs in order to self-record their behaviour and health measurements. A study on the interpretation of self-reporting argued that self-reporting has become a habit for some consumers because it is based on continuous action of checking the technology which eventually becomes automatic as a learned response (Gardner \& Tang, 2014). Habit has been applied to the adoption of technology and proved to be a significant construct that affects consumers' behavioural intention in other fields such as smartphone addiction (Chen et al., 2015), extensive use of mobile TV (Wong, Wei-Han Tan, Loke, \& Ooi, 2014), and use of near field payments (Morosan \& DeFranco, 2016).

\section{Privacy - Personalization Paradox}

To provide personalized, real-time feedback of health information for each user, WTDs record and store personal health data via the cloud, which raises privacy concerns that should also be addressed when referring to the adoption and use of wearable technology. The growing popularity and use of WTDs has increased the ability to collect and store more information from 
the user, which includes clinical, behavioural and self-monitored data (Lewy, 2015). Today, the devices allow the collection of large amounts of health data that was previously not possible. Massive collection of data with WTDs helps companies develop new tools for health analysis. Clinical and medical research practices benefit from these new tools. As the innovative technology allows for a large collection of data health data it also allows feedback of more personalized information for each user based on their individual needs. Users are empowered to manage their health, which they can do either independently or together with their healthcare providers. Hence, the new developments in wearable technology allow the gap to be closed in the relationship between healthcare and patients by improving and changing healthcare delivery models. While most consumers are growing accustomed to sharing a large amount of personal information on their numerous connected technological devices, consumers still have high requirements of privacy protection. This phenomenon has been termed the "privacy paradox" (Norberg, Horne, \& Horne, 2007).

In order to send a customized response to each user, the company must identify the needs and the context which each user requires, but in order to do so, personal data needs to be collected (Ho, 2012). Personalization involves customizing the user interface to each of the users' needs (Albashrawi \& Motiwalla, 2015). However, it requires users to disclose more personal information, which raises privacy concerns (Xu, Gupta, \& Pan, 2009). For example, consumers share their personal and health information (e.g., steps, location, health status, preferences, living habits, etc.) with their service providers so that they can receive more personalized services and feedback based on their health needs. However, information sharing between users and service providers results in privacy concerns relating to the data collection, which, as Awad (2006) suggests, results in an apparent "personalization - privacy paradox". 
In order to receive customized information, each consumer must disclose their private health related information via WTDs. On one hand, consumers may identify a positive value in receiving personalized feedback regarding their health, while on the other hand, privacy concerns about disclosing their personal information may make them reluctant to use this technology $(\mathrm{Xu}$, Luo, Carroll, \& Rosson, 2011).

Various privacy-enhancing methods have been employed to deal with privacy concerns in the context of personalization (Kobsa, Cho, \& Knijnenburg, 2016; Toch, Wang, \& Cranor, 2012). More recently, companies are using highly secure cloud-storing models to securely collect and store consumers' personal information (Guo \& Poole, 2009). Cloud-storage is a service in which data is stored, managed and backed up remotely from the device via the Internet. In a study by Kobsa et al. (2016), researchers looked at personalization, and found that consumers' privacy concerns are lowered when they are using a reputable company (e.g., Amazon), while unknown companies were found to increase privacy concerns. Researchers also found that for "cloud-based" personalization, privacy concerns were high for both reputable and unknown companies. In the context of this study, it is not always clear to the consumer where the information is stored when they use WTDs and health apps (CitizenLab, 2016). Therefore, this paradox is applicable in the context of this study in order to better understand consumers' behavioural intention to give up their health data in return for personalized feedback.

Ho et al. (2012) investigated the effects of location personalization on individuals' intention to use mobile services. Researchers found that individuals are naturally inclined to use personalized mobile services that help them connect with one another. Researchers also confirmed that the use of personalization technique should be reinforced by a proactive approach to protect data privacy. In another study, Aguirre et al. (2016) investigated personalized 
communication through digital media and found that personalization can both enhance engagement with the firm and raise privacy concerns in consumers, confirming the personalization-privacy paradox. Researchers suggest that the benefits of personalization can vary depending on the medium through which the message is communicated, and privacy concerns should be addressed accordingly.

Several studies suggest that the data collected by organizations must be used in a strategic manner to balance the personalization-privacy paradox (Aguirre et al., 2016; Guo et al., 2015). In other words, effective and well organized management of personal information must be reinforced in order to protect privacy and security of users. Medical and financial information collected from individuals is considered to be more sensitive than information about their demographics and shopping preferences (Sergueeva \& Shaw, 2016; Sheehan \& Hoy, 2000). According to Sheng (2008), sharing of personal health and medical information raises privacy concerns in users. Consumers fear that collection of personal health and medical information may be accompanied with a possibility of this data being shared with a third party (Zhou, 2012). Therefore, when consumers utilize these personalized services, they are reluctant to reveal their personal information in the first place (Guo et al., 2015) and seek to reveal as little personal information as possible. This paradox has been the topic of extensive research (Awad \& Krishnan, 2006; Chellappa \& Sin, 2005; Guo et al., 2015; Sutanto, Palme, Tan, \& Phang, 2013; $\mathrm{Xu}$ et al., 2011). However, review of previous literature suggests that there are no studies that have incorporated the personalization-privacy paradox in the context of WTDs adoption.

\section{Personalization}

Personalization is about understanding the needs of each individual customer and knowledgeably addressing these needs in a specific context by the service provider $(\mathrm{H}$. Liang, 
Saraf, Hu, \& Xue, 2007; J. Xu, Benbasat, \& Cenfetelli, 2014). Currently there is little academic literature on HIT personalization. This study adopts the definition of personalization as "the extent to which the services provided by providers are based on individual's preferences" (Salo \& Karjaluoto, 2007). This definition is also adopted by Guo et al. (2015). Hence, in the context of wearable technology, personalization is the facilitation of appropriate health metric services for specific health preferences and/or condition via WTDs or the apps that are linked to a mobile device.

Today, without personalization of IS, most customers often feel overwhelmed by the amount of information presented to them (Murray et al., 2010). Previous research found that apps with a personalization capability increase customer satisfaction and loyalty and result in continued usage (Albashrawi \& Motiwalla, 2015). Personalization has been studied in IS and service studies with results showing that there is a positive influence on trust (Komiak \& Benbasat, 2006), adoption (Sheng et al., 2008), satisfaction (H. Liang et al., 2007), attitude (Jun Xu \& Quaddus, 2007), and behavioral intention (Bauer, Reichardt, Barnes, \& Neumann, 2005; Guo et al., 2015; Neal \& Carey, 2004). Xu et al. (2014) has suggested that a more comprehensive theory of IS is required that includes the concept of personalization.

In the context of this study, users personalize WTDs according to their health needs to efficiently self-monitor their health. Due to the personalization of WTDs, devices are designed to integrate seamlessly into the everyday lives of users. Services and applications that WTDs provide are tailored to each user's health needs. A consumer may choose to use or not to use personalized services, the choice depends on the perceived value of the service of each user (Chellappa \& Sin, 2005). For example, different health apps are available to download onto smart watches, and WTDs give very personalized feedback of information based on collected 
data of each user. Consumers may also choose which of the health metrics they wish to monitor (e.g., heart rate and glucose, or sleep pattern). This way user does not get overwhelmed with feedback information of all of the collected data. Thus, personalization may entice consumers to prolonged use of WTDs. However, there has been no academic research on consumer's need for personalized services in healthcare or how personalization services are used in the presence of privacy concerns.

\section{Privacy concerns}

The privacy-personalization paradox suggests, when users seek personalized services, privacy concerns arise simultaneously. According to Park (2014), personalization increases acceptance and use of Information Technology (IT). However, at the same time it raises concerns about the type of information that it collects and the process that it entails, which can restrain consumers from further use of IT (Dhar \& Varshney, 2011). This process is presumed to create conflict between personalization and privacy (Albashrawi \& Motiwalla, 2015).

The issue of privacy concerns arises from the fact that consumers have less control of the data that is collected by WTDs. WTDs store consumer data either locally or in the cloud. Locally storing the data, meaning that the data is saved on their devices, increases the vulnerability of data being attacked by malware and increases the opportunity of data being physically stolen

(Goh, 2015). Cloud based services, which operate by sending data from the device to the cloud, also create an opportunity for hacking of the device and due to the limited software capabilities of WTDs, it is difficult to provide secure data transfer (FTC Staff Report, 2015; Maddox, 2014). In both processes, consumers rely on technology and its infrastructure to securely store their health data. According to Cho, Rivera-Sánchez, \& Lim (2009), conflict arises when users exhibit high levels of privacy concerns because of their strong inclination towards privacy-preserving 
behaviour. Hence, users become reluctant to use the system in the future.

Privacy, according to Varshney (2014), is an individual's right to withhold personal information to keep their private information private and away from others. Privacy concerns relate to the risk of unwanted disclosure of personal information (Zhou, 2011). These concerns are relevant when studying users' intention to use WTDs, as location and personal information are automatically collected and stored and therefore potentially available to non-authorized parties.

Previous studies identified that privacy concerns directly affect behavioural intentions to adopt various information systems such as Location-Based Services (Mao \& Zhang, 2013; Xu et al., 2009), mobile banking (Luarn \& Lin, 2005) and e-health records (Angst \& Agarwal, 2009). Consumers are more willing to share information if they trust the other party, as they perceive their privacy risk to be less (H. Xu, Teo, Bernard, \& Agarwal, 2012). Consumers are influenced by the perceived value of the personalized services while giving up their privacy in the form of personal information. In addition, Dinev \& Hart (2004b) suggested that if individual perceive that they have some control over the use of their personal information, their privacy concerns are lowered. In a study of health wearables, Gao et al. (2015) determined that privacy risk has a significant effect on an individual's behaviour intention. Hence, due to the sensitivity of the data, the construct of privacy concerns is included in the theoretical framework as companies need to show consumers that the value of using WTDs overcomes the risk of data disclosure to nonauthorized parties.

Previous HIT studies of privacy - personalization paradox found that privacy concerns and perceived personalization directly influence consumer behavioural intention (Guo et al., 
2015; X. Guo, Sun, Yan, \& Wang, 2012). However, there is no previous research on the paradox and the effect on individuals' intentions to use WTDs. Further studies are needed in order to understand privacy personalization paradox in the context of use of WTDs in healthcare.

\section{Health Consciousness}

This research adds the construct of health consciousness to explain health behaviour, and extend the research into consumers' intention to use WTDs.

Kraft and Goodell (1993) have described the concept of health consciousness as a "Wellness-Oriented" lifestyle that describes the degree that individuals are concerned with their own health. These individuals are conscious of their food consumption, physical activities, and their living environment. Previous research indicates that health consciousness has the potential to influence health behaviour (J. Cho, Park, \& Lee, 2014; Hong, 2011; Jayanti \& Burns, 1998). Jayanti and Burns (1998, p. 10) described health consciousness as "the degree to which health concerns are integrated into a person's daily activities". In other words, individuals with higher levels of health consciousness tend to incorporate a healthy lifestyle into their daily lives, and in fact, it may influence their daily routines (Tai \& Tam, 1997). Individuals are more likely to have healthier habits, exercise more often, and seek information on healthy living (J. Cho et al., 2014).

In a study by Hong (2011), researchers have argued that health consciousness is a powerful predictor of health behaviours. Previous research also suggests that health consciousness is an important factor in predicting various health attitudes and health behaviour (Michaelidou \& Hassan, 2008). Highly health-conscious consumers are more inclined to adopt a healthy lifestyle, such as consuming organic produce and exercising regularly (Mai \& Hoffmann, 
2012). Several studies argued that level of health consciousness is related to how individuals seek and respond to health information (Dutta-Bergman, 2004, 2005; Hong, 2011; Iversen \& Kraft, 2006). For instance, Dutta-Bergman (2005) identified that health - consciousness has an influence on behavioural intention of health information seeking. Hence, increased health consciousness in individuals increases the likelihood of their engagement in cognitive and behavioral activities to benefit their health, such as seeking information on health or engaging in physical activity.

There are studies that have incorporated health consciousness in the HIT context. The role of health consciousness was examined in the use of health apps, with research indicating that individuals' health consciousness is significant in determining behavioural intention in the use of health apps (J. Cho et al., 2014). Another research demonstrated that individual's behavioural intent is influenced by their health consciousness to seek online health information (Xiao, Sharman, Rao, \& Upadhyaya, 2014).

Although previous studies have confirmed the influence of health consciousness on health behaviour and intention to use other forms of HIT, there is no previous research on health consciousness and its influence on individuals' intentions to use WTDs.

Given that WTDs are an emerging technology in healthcare, technological and healthcare factors are predicted to significantly influence behavioural intention in individuals. Consumers may also display privacy concerns as the devices collect user's health information in exchange for a personalized feedback response. Therefore, an integrated framework with technology acceptance, health behaviour, and privacy-personalization context is developed to explain consumer intention to use WTDs. 


\section{RESEARCH MODEL AND HYPOTHESES}

To test consumers' intentions to use WTDs among the general population, this thesis builds on the foundation of UTAUT2. Because consumers are concerned with their health and are sometimes careful about sharing data, this study is extended UTAUT2 with the construct of health consciousness and constructs from the personalization-privacy paradox

\section{UTAUT2}

Among technology acceptance models, I selected UTAUT2 which is a comprehensive model to explain technology acceptance and use by consumers (Wong et al., 2014). UTAUT2 has seven factors that directly influence intention to use (ITU): these are Performance Expectancy (PE), Effort Expectancy (EE), Social Influence (SI), Facilitating Conditions(FC), Habit (HB), Hedonic Motivation (HM), and Price Value (PC) (Venkatesh et al., 2012). The detailed explanations for each construct are given as follows.

\section{Performance Expectancy (PE)}

Performance expectancy is defined as "the degree which using a technology will provide benefits to consumers in performing certain activities" (Venkatesh et al., 2012, p. 159). This construct measures the effectiveness of the technology. In the context of this research, the effectiveness of WTDs can be captured by how effective and beneficial it is to use the devices to help consumers to monitor their health condition, fitness progress and make personal fitness goals, etc. In order for consumers to use these devices they need to be confident that the technology efficiently and accurately collects their data while effectively provides them with output results based on the health data that is collected. In other words, consumers must be confident that WTDs provide a larger benefit by digitizing their health data than when they are 
not wearing the devices and must self-track their health manually. WTDs provide a comfortable means to collect "detailed longitudinal data" to identify and track a patient's progress (Piwek et al., 2016). For example, WTDs have the ability to diagnose sleep apnea and improve sleep quality based on the measurement of heart rate, breathing volume and snoring, which is far more efficient and comfortable than undergoing polysomnography (Harrington, Schramm, Davies, \& Lee-Chiong Jr, 2013).

Empirical studies have shown performance expectancy to have the largest effect on intention to use (ITU) (Morosan \& DeFranco, 2016; Venkatesh et al., 2012). Meta-analysis of UTAUT (Dwivedi, Rana, Chen, \& Williams, 2011) found performance expectancy to have most influence on behavioural intentions. Sun et al. (2013), empirically compared different technology adoption theories and validated perceived usefulness to be an important construct in health technology adoption. UTAUT2 (Venkatesh et al., 2012) supports a positive effect of performance expectancy on behavioral intention. Therefore, I hypothesize:

\section{H1: Performance Expectancy positively affects consumers' intention to use WTDs.}

\section{Effort Expectancy (EE)}

Effort expectancy is defined as the "degree of ease associated with the use of the system" (Venkatesh et al., 2003, p. 450). In the context of this study, EE measures the effort it takes to monitor health with a WTD and its smartphone application. To efficiently use WTDs, the devices are paired with users' health apps on their smartphones. The WTD records health data and the data is then stored on the smartphone app. The data is analyzed by the app and the results based on the individual's health needs are then displayed, either via the app or the WTD. Hence, in order to use WTDs, consumers must be comfortable with using their smartphone devices. If 
consumers have already deployed smartphone apps, they will find it easy to learn to use a new technology that has to be paired up with their existing smartphone: it will not be a barrier to them. The use of WTDs is similar to smartphones, and when personalized, WTDs are easily integrated into the consumer's daily routine.

Additionally, previous studies have identified that the relationship between EE and intention to use (ITU) has not been as strong as between PE and ITU (Khechine, Lakhal, \& Ndjambou, 2016; Sun et al., 2013). Some studies have shown that EE is no longer a barrier to users for the adoption of modern technology because consumers have enough experience and knowledge with the use of one technology to be able to learn and use another technology (Gao et al., 2015; T. Wang, Jung, Kang, \& Chung, 2014). Meta-analysis of UTAUT by Dwivedi (2011), where researchers compared the four constructs, determined EE to have the least significance on behavioural intention. Another meta-analysis of UTAUT by Khechine, Lakhal \& Ndjambo (2016) showed that IT use in healthcare is predicted by FC, rather than PE, EE, and SI. Additionally, several studies found that effort expectancy does not have a significant impact on IT use (Huigang Liang, Xue, Ke, \& Wei, 2010; Rodrigues, Sarabdeen, \& Balasubramanian, 2016) and WTDs (L. H. Wu et al., 2016). Additionally, Gu et al. (2016) has excluded the construct from the research model all together. Therefore, the EE construct is excluded from this study.

\section{Social Influence (SI)}

According to UTAUT2, social influence affects the behavioural intention to use technology. Social influence refers to the extent users are influenced by others who are important to them (Venkatesh et al., 2003). 
Previous research has shown that when users share their goals with others on social media or when they compete for goals among others, the users are more likely to commit to achieving the goals they set for themselves (Locke \& Latham, 2002). The mechanism to explain this phenomenon lies in users' fear and guilt of losing their social capital from social network through failing to reach the goals they set for themselves. Hence, expressing goals via social networks, such as Facebook or Twitter, and collaborating with others, increases the likelihood of enacting behavioural change. For example, one of the marketing tactics of Fitbit is to encourage their users to compete against each other and share their fitness results online (FitBit, 2017), hence influencing others to purchase the technology in order to participate with friends.

Although some previous studies on professionals' health technology acceptance and use found that social influence is not significant on behavioural intention to adopt technology (Chau $\& \mathrm{Hu}, 2001$ ), more recent studies have supported that social influence can alter user beliefs, attitudes, motivations and intentions (S. A. D. Brown, 2010; Piwek et al., 2016; Teh, K., Cheong, \& Yap, 2014). Recent studies of technology adoption in healthcare using UTAUT2 demonstrated that social influence is a significant factor to adoption intention (Gao et al., 2015; Sun et al., 2013). As well, recent improvements in WTDs allow users to display the results of their physical activity via social media, and to participate in friendly competitions among each other (e.g., Fitbit). In the context of WTDs, individuals tend to make their decision based on the suggestions and opinion of others. For example, an individual may start using a WTD based on the recommendation of his or her doctor to monitor a specific health issue, or to help maintain a healthy lifestyle.

WTDs are visible when worn by consumers, as they are required to be worn continuously throughout the day. Consumers may find the technology appealing or become curious and ask 
about the technology. As the devices become widely adopted and used among consumers, with the posting of fitness results and updates of their health and fitness progress, they also post social statuses about the devices and their functionality via social media. Social influence is strongly supported by previous studies (Gao et al., 2015; K. J. Kim \& Shin, 2015; Sun et al., 2013; Venkatesh et al., 2012). Therefore, I hypothesize:

H2: Social influence positively affects consumers' intention to use WTDs

\section{Facilitating Conditions (FC)}

Facilitating conditions refer to the perception of consumers that the resources and support are available to use the technology (Venkatesh et al., 2003). In other words, consumers need to be assured that FC conditions are in place (Rhee, 2008; Venkatesh, 2014). When using WTDs, consumers expect the technology to function effectively and flawlessly. For example, a consumer may decide to monitor their heart rate because of a previous heart attack, or to monitor calorie intake and physical activity in order to lose weight. On the occasions when they might require support, either for initial assistance or for help if something is not working correctly, they expect assistance to be available and any issue to be resolved speedily, such as assistance will be provided when they need to speak to someone either via a phone call, live chat, or an e-mail. They also expect that manufacturers are able to provide and assist with all the necessary steps in cases where WTDs have to be returned, exchanged, or fixed. Users may have some doubts on the infrastructure of the companies to deal with technical issues, and WTDs capabilities. If FC conditions are not available, users may be reluctant to use the technology.

In the context of healthcare, consumers need to be assured that a medical professional will be able to assist them with their needs. For example, a doctor must also be able to read the 
output on the medical app in order to address the needs of patients. Consumers must be assured that all the necessary help is available. Hence, I hypothesize:

H3: Facilitating Conditions positively affects intention to use wearable device.

\section{Hedonic Motivation (HM)}

Another important factor in UTAUT2 is hedonic motivation, which refers to the pleasure or enjoyment derived from using the technology (Venkatesh et al., 2012). The construct is derived from the psychological theories such as playfulness theory and flow theory (Wu et al., 2016), and used to discover individual's emotional motivation towards a product. Therefore, it is important to find what current users find enjoyable in using the WTDs to facilitate their future use of the technology.

Previous studies have shown that hedonic motivation is significant in determining an individual's acceptance of a technology (S. A. Brown \& Venkatesh, 2005). This has been supported in the adoption of medical wearable devices (Gao et al., 2015) and virtual health services, such as mHealth (MäNtymäKi \& Salo, 2011). In the context of healthcare, individuals would pay more attention to the enjoyment of the products since a wearable device is different from other types of health IT products in terms of usage and functionality. For example in addition to collecting and displaying real-time data, it compiles, organizes and compares health and fitness information through pie charts, bar graphs and colourful displays (Salah, 2014) all of which add to enjoyment.

Today, the technology does more than collect basic data. Not only do users directly check their own physical conditions such as sleep, mood, pulse and diet (Ledger, 2014), but the devices such as FitBit, allow consumers to compete among each other. Recent gamification of WTDs has 
allowed consumers to participate in online competitions, where the results of their physical activity is compared and posted on social media websites, or shared with other users via a smartphone app.

The WTD can be used, in conjunction with a paired smartphone, as a communication device to stay in touch with friends, via texting. These attributes can make a WTD more than just a healthcare device: they contribute to the overall enjoyment of the technology, as it feels "fun" to use. Therefore, I hypothesize:

H4: Hedonic motivation positively affects individual's intention to use wearable device.

\section{Habit (HB)}

Neuroscientists have spent decades studying the process of habit formation, as it is a complex process that occurs over time. Habit has been defined as the extent to which people tend to perform a behavior automatically because of previously learned behaviour (Limayem, Hirt, \& Cheung, 2007), and this terminology is associated with automaticity (S. Kim, 2009). Venkatesh et al. (2012) suggest that pre-existing experience with technology has the potential to positively influence a user's current behaviour.

Individuals might get used to wearing WTDs and adjust their behavior accordingly. For example, when WTDs first became available on the market, consumers were slow to adopt them (Ledger, 2014). They might have been skeptical about their use to monitor their physical activity and health. But, as consumers have become more conscious about their health, they are now more accustomed to incorporating WTDs in their everyday lives. The current wearable technology market continues to grow and expand, indicating the skepticism that previously existed has now decreased. 
In psychology, habit is defined as routine behaviour that is triggered by situation cues, which is then followed by a positive reward. In the context of this research, individuals that continuously wear WTDs, may adjust their behaviour. WTDs can facilitate the process of formation of a positive habit. For example, individuals who wish to lose weight may use WTDs to track their health and fitness activity. Continuous notifications of their daily activities, and overall progress is served as a reward. This process may trigger behaviour that could lead to positive habit of continuous use of WTDs in order to continuously receive rewards in the form of progress reports. The rewards could also come in the form of posting progress via social media, and comparing progress against peers. The recent upgrade of WTDs, which combines the playful design and a feedback mechanism, resembles game design. This type of design and connection via social media may contribute to habit formation in consumers.

Previous studies on wearable devices have excluded habit because the technology was still new on the market. Today, the technology has been around for several years, and users have become accustomed to using the device. The use of WTDs together with smartphones has encouraged consumers to continuously wear the device throughout the day to record their physical activity and accomplishments in order to be able to complete with their peers (Ledger, 2014). Therefore:

H5: Habit positively affects individual's intention to adopt wearable device.

\section{Price Value (PV)}

Cost and pricing structure are important factors in the adoption and use of consumer technology. Consumers bear the costs associated with a technology purchase and use of the devices (Venkatesh et al., 2012). According to a Nielson survey, nearly half of American's 
questioned $(n=2,313)$ have shown an interest in purchasing a wearable technology device in the future, but $72 \%$ of those that showed interest put cost as a limiting factor as they wish the technology would be less expensive (Nielsen, 2014b). Venkatesh et al., (2012) suggested that PV is perceived as positive when benefits of using a technology are perceived to be greater than the incurred costs. On other words, if individuals feel that the technology is priced too high, but if they perceive the benefits to be larger than the incurred cost (e.g., leading to a healthier lifestyle and saving lives), they are more likely to adopt the technology. In the context of this study, individuals may find WTDs to be costly, but they will also evaluate all the attributes of the WTDs in order to determine if the benefit from using the devices will outweigh the costs. If individuals find that WTDs high a high potential to improve the quality of their lives and their health, they are more likely to adopt and use the technology. For instance, through the recording of health measurements, individuals will be able to keep track of the health or fitness progress, while healthcare providers will be able to track patient's health via statistical output of the data more efficiently and not rely on patient's complaints or the manual recordings of patients' health.

Accordingly, Venkatesh et al., (2012) associates PV with a positive influence on behavioural intention. Hence:

H6: Price value positively affects individual's intention to use wearables

\section{Privacy-personalization paradox}

\section{Personalization}

Personalized technology and services are becoming increasingly popular (Toch et al., 2012). Personalization involves customizing the feedback context to each of the user's needs. Personalization exists in many fields and has previously been defined in the literature as 
delivering "the right content to the right person in the right format at the right time" (Sun et al., 2013). Many studies have shown that personalization is a key factor for providers (Aguirre et al., 2016; Guo et al., 2015; Sutanto et al., 2013). In the context of WTDs, devices can deliver services such as personalized, real-time feedback based on collected data by the sensors for specific health conditions and preferences (Piwek et al., 2016). Park (2014) study found that personalization influences consumer behaviour intention and it increases continued use of IT. WTD's personalized services can efficiently increase the effectiveness of the interaction of the WTD provider, and hence could lead to higher satisfaction among users, thereby positively influencing intention to use. For example, potential users might prefer to only monitor their heart rate due to a history of a recent heart attack, thereby protecting themselves from the occurrence of another heart attack. WTDs can enact this functionality by only tracking the heart rate data and promptly delivering the relevant information to the user throughout the day via notifications. The user will be notified of any sudden fluctuation in heart rate and will therefore be able to seek help from their healthcare provider prior to the situation worsening. Based on this observation, intention to accept the technology is enhanced due to the personalized, real-time feedback of WTDs. Hence:

H7: Personalization positively affects behaviour intention to use wearable device

\section{Privacy concerns (PC)}

In the past, privacy has been defined as the right to withhold one's information (Dinev \& Hart, 2004a). The privacy - personalization paradox suggests that in order to get personalized services, consumers must disclose their personal information, which in the case of WTDs is health data (Awad \& Krishnan, 2006). Previous studies concluded that privacy concerns have a direct influence on adoption intention in web-based systems(Dinev \& Hart, 2004a; X. Guo et al., 
2012; Sutanto et al., 2013). The findings of these studies suggest that, online, consumers' intentions to use personalized services are negatively affected by their privacy concerns. However, individuals might be willing to provide personal information in order to receive personalized feedback based on individual needs. As long as consumers perceive technology as useful and the perceived benefits of using WTDs are high, the privacy concerns decrease. Thus, this increases the adoption rate of WTDs. In the context of this study, consumers need to be confident that their personal data will not be misused or accessed by non-authorized individuals. Because of the sensitive nature of health information:

H8: Privacy Concerns negatively affect consumers' intention to use WTDs.

\section{Health Consciousness (HC)}

Previous studies showed a significant relationship between health consciousness and behavioural intention (J. Cho et al., 2014; Hong, 2011; Mai \& Hoffmann, 2012). More recent research suggests that health consciousness is an important factor in predicting a variety of health behaviours (Meng, Guo, Peng, Lai, \& Vogel, 2016). For example, individuals with high health consciousness are more likely to adopt good practices, such as regular exercise (Mai \& Hoffmann, 2012), and more likely to read health related articles or watch health related television shows (Hong, 2011). In a study by Cho et al. (2014), researchers have explored and confirmed a direct relationship between health consciousness and behavioural intentions to use health apps such as mHealth.

In the context of this study, I predict that when consumers are conscious about their personal health, they are more likely to use WTDs to monitor their physical activity, and/or vital signs on a regular basis. Therefore:

H9: Health consciousness positively affects the intention to use WTDs 


\section{RESEARCH MODEL}

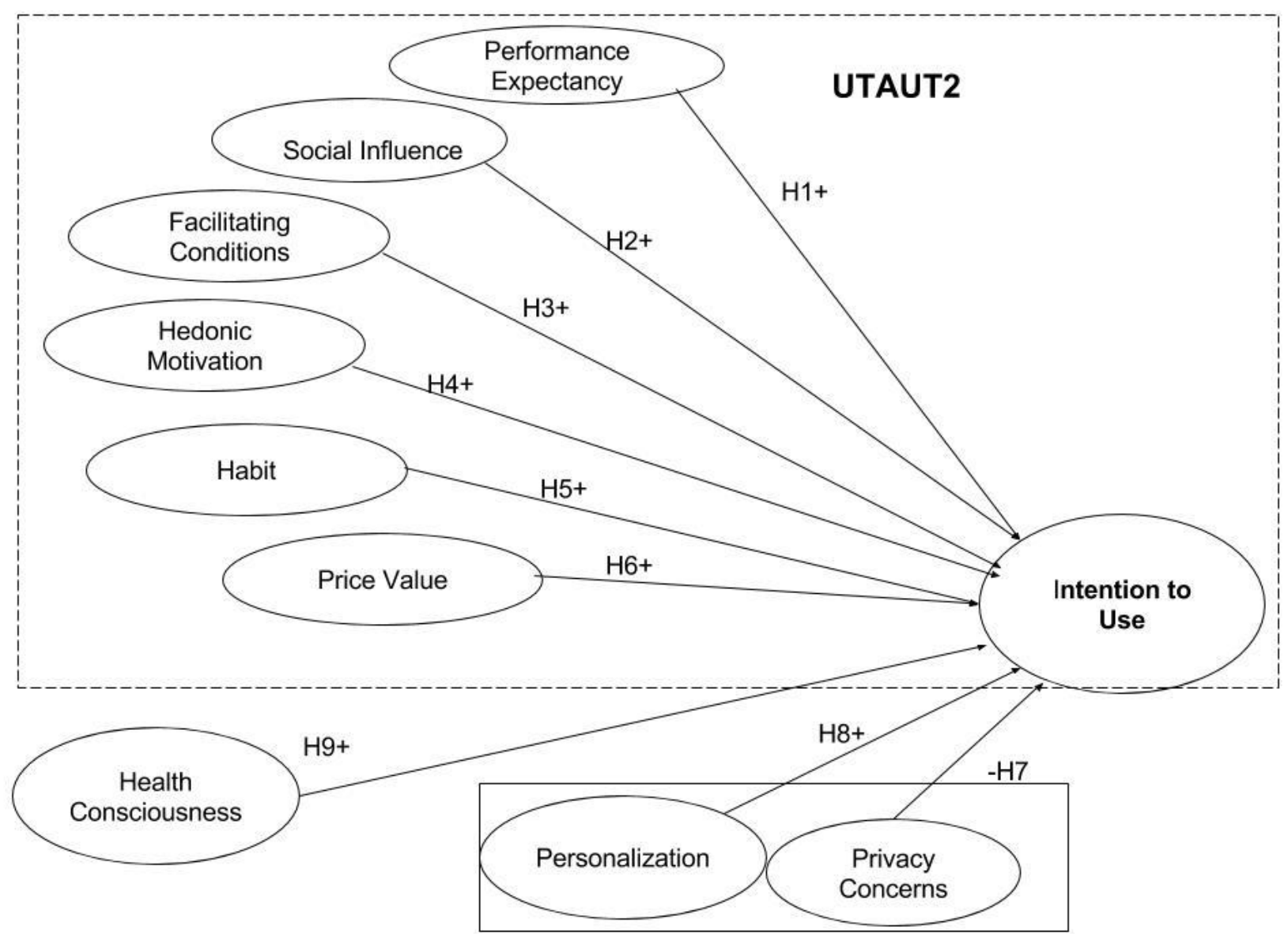

Personalization-Privacy Paradox

Figure 2: Research Model 


\section{RESEARCH METHODOLOGY}

In this chapter, the research methods used to test the hypotheses are explained. As discussed earlier in this document, the nature of the research questions is predictive and we therefore follow a deductive research strategy. Quantitative methods were used for data collection, reduction and analysis. This research methodology is compatible with deductive research strategy, as it uses validation and reliability tests to determine the validity of the research model.

\section{Research Methodology}

The purpose of this thesis is to add to the body of knowledge by identifying the factors that affect behavioural intention to use wearable technology devices (WTDs). The research is deductive and is built upon prior knowledge and existing theories in technology, the privacypersonalization paradox and health theories (Gould, 1989; Guo et al., 2015; Venkatesh et al., 2012). Therefore, a hypothetico-deductive approach is applied to the theoretical knowledge of HIT adoption. The beginning of this scientific process involves the identification of a gap in the literature. It follows the process that involves the formulation of theory, the generation and testing of hypotheses, and the presentation of the research findings.

In social sciences, the paradigm adopted by the researcher needs to be declared. 'Paradigm' is defined as a consensual set of beliefs and practices that influence how researchers select questions they study and the methodology they choose to collect and analyse their data (Morgan, 2007). Thomas Kuhn explained that paradigms represent the researchers' beliefs of how their results contribute to the body of knowledge. Kuhn (1996) identified that a paradigm is composed of three components: Ontology, epistemology, and methodology. Ontology is an explanation of the social world, and answers the question of "what is real?" according to the 
beliefs of the researcher. Epistemology is identified as the set of assumptions about knowledge and it answers the question "how do we know what is real?" The epistemology adopted by the researcher depends upon their ontological beliefs and therefore both ontology and epistemology influence the researcher's decision of which methodology to apply in their research (Rayner, 2011).

This study is guided by the worldview of critical realism (Bhaskar, 1975; Burrell \& Morgan, 1979). Critical realism combines ontological realism and epistemological constructivism. Maxwell (2012) suggests that ontological realism is grounded in the "belief that there is a real world that exists independently of our perceptions and beliefs" (2012, p. 43), while constructivism assumes that "our understanding of this world is inevitably our construction" (2012, p. 43). The combination of realism and constructivism in the critical realism approach suggests that the reality constructed by the researcher is independent from an observable existing reality (Burrell \& Morgan, 1979).

Critical Realism assumes that researchers cannot explore all possible mechanisms that contribute to the occurrence of an observed event, but they can contribute to discovering some of the mechanisms (Bhaskar, 1975). A critical realist viewpoint is appropriate for this study because it explores how individuals use wearable technology in the context of healthcare. Events are observed, with the understanding that their interpretation depends upon the perception of the researcher who is engaged in observation (Morgan, 2007). Critical realism accounts for empirical data and social constructs, and is often applied within social science research methodology (Morgan, 2007).

The main purpose of this quantitative, non-experimental study is to determine the extent to which the variables of Performance Expectancy (PE), Facilitating Conditions (FC), Social 
Influence (SI), Hedonic Motivation (HM), Habit (HB), Price Value (PV), Personalization (PR), Privacy Concerns (PC), and Health Consciousness (HC) are predictive of intentions to use (ITU) WTDs. In other words, its purpose is to test nine hypotheses of the research model. A quantitative design was chosen for this research because it builds upon prior quantitative research and existing theories. It is also the selected method of analyzing data collected through surveys (Leedy \& Ormrod, 2001). Quantitative research involves the collection of data that can be quantified and subjected to statistical analysis in order to justify or reject hypotheses (Creswell, 2013). This study is built on a body of prior knowledge, existing theories in consumer adoption of technology, personalization - privacy paradox and health-consciousness.

Quantitative methods are appropriate because it aligns with prior research methodologies that have been used to study theories that are similar to that proposed in this study (e.g., (Venkatesh et al., 2012)).

A quantitative study is defined as "inferring evidence for a theory through measurement of variables that produce numeric outcomes" (Field, 2013, p. 882). This research technique allows data collection using pre-validated constructs to be quantified and subjected to a statistical analysis to produce valid results (Yoshikawa, Weisner, Kalil, \& Way, 2013). Furthermore, statistical measures of adoption and use of technology provide more objective results than an interpretive qualitative approach (Yoshikawa et al., 2013). A quantitative approach gives a higher statistical power and precision than a qualitative method because of the larger number of cases that can be collected (Yoshikawa et al., 2013). Quantitative methods allow for the generalization of the results to a similar population as a whole. Higher statistical power is important to determine the relationship between independent and dependable variables, which are appropriate for this study (Jörg Henseler \& Sarstedt, 2013). 


\section{Item development}

To test the proposed research model, a survey was conducted that included items for all the constructs involved in the conceptual model. As all of the measures for the constructs in the research model are available in prior studies, the items (APPENDIX) were adapted from previous published studies with minor modifications to fit into the context of WTDs.

Items were measured on a seven-point Likert scale with 1 being "strongly agree" and 7 being "strongly disagree". Initial consultation was done with subject matter experts to examine the logical consistency, contextual relevance, and question clarity of the measurements. Their suggestions were incorporated into the next version of the questionnaire. In addition, a pilot study with 20 participants was conducted to collect more feedback to further improve the questionnaire. The comments and suggestions from subject matter experts such as formatting of the questionnaire and clarity of the items, were incorporated. The main study was then launched after finalizing the questionnaire.

\section{Study Design and Procedure}

Because human subjects were involved in the study, approval from Ryerson's Research Ethics Board (REB) was sought prior to the distribution of the questionnaire. The questionnaire was distributed through electronic mail. A document with description, sample products, and application of the WTDs was attached to the recruitment e-mail, which was presented to each participant prior to the start of the survey. The introduction also included goals of the research project, privacy measures, and the survey page. Respondents who completed the survey were awarded points. The recruitment and rewards for participation were facilitated by Qualtrics, 
which is a company that provides panel management software that allows researchers to assemble and manage their panel(s) (Qualtrics, 2017). Qualtrics allows for pre-recruited, internet-enabled panels with online surveys, eliminating the lengthy recruitment process associated with research. Qualtrics is an online survey company that facilitates not only the data collection process, but also the preparation, distribution and data collection of an online survey. Prior to data collection, an online survey link was created via Qualtrics.com website. The online link lead to a document that consisted of an introduction letter, consent form, and the survey instrument. Qualtrics' project managers and programmers were randomly assigned to the study. Once the study's participant parameters were given to a project manager, the participants were then contacted via e-mail containing the anonymous link to the survey. No personal or identifying information was collected in this survey. Participation in this study was voluntary. When participants agreed to participate in the study by giving their consent, they proceeded to complete the survey. Once the survey was completed, Qualtrics collected and stored each response data on their server. After the collection of data was complete, the results were then downloaded from Qualtrics.com into an Excel formatted document. The data in the document was then cleaned and later analyzed by the researcher.

Using survey methods to collect our data is appropriate for several reasons. Due to the quantitative nature of this study, the survey describes numerical distribution of variables in the population (Groves et al., 2011). Research has shown that the data reliability obtained from online surveys is better than the reliability of data obtained from telephone surveys (Braunsberger, Wybenga, \& Gates, 2007) or from surveys administered on paper (Greenlaw \& Brown-Welty, 2009) because of the predetermined quality procedures in place. For example, attention filters were placed throughout the survey to eliminate participants that were not paying 
attention to the questions. Attention filters are questions where participants are asked to choose a specific answer (e.g., "please pick strongly agree to continue"). If any answer other than "strongly agree" is selected, the survey is automatically terminated and the participant does not receive any incentive.

Surveys gather information from a sample of members, based on measuring real-world observations that can be generalized to the population from which the sample was drawn. Survey data allows for the collection of a large amount of data in a short time at a relatively low cost with better response rates (Andrews, Nonnecke, \& Preece, 2003) and less effort to administer the survey by the researcher. Online surveys are found to be most convenient for the respondents. Data is immediately collected, stored and efficiently digitized for usage with statistical software. For these reasons, utilizing Qualtrics' expert panels represented an effective approach to data collection than the alternatives.

Participants were selected from the general population of the United States of America, whose ages were between 18 and 81 years old. The prerequisite for survey collection was that only half of the participants must own WTDs. A total of 330 responses were collected and used in the data analysis.

\section{Data Preparation}

Data preparation is an essential step in quantitative research. Improper treatment of the data prior to analysis can confound the findings. Collected data must be presented in a numerical format in order to be understood by the statistical program used for the analysis.

One of the advantages of using online survey software such as Qualtrics is its ability to handle data efficiently. Once the collection of data was completed, results were downloaded into 
an Excel file format. The data was pre-coded. In this research, I pre-coded scale points that are specific for this study's questionnaire. Variables measured with interval and ratio scales are used with multivariate analysis. The use of Likert scales is a very important factor in fulfilling the requirement of equidistance (Hair, Hult, Ringle, \& Sarstedt, 2014). This study used a seven point Likert scale.

Once downloaded into Excel, the variables were then changed into three to four characters to satisfy the restrictions of the statistical software. After the survey was completed, the data was cleansed prior to statistical analysis.

\section{Straightlining}

When primarily using surveys as the source of data collection, the responses must be validated. According to Kaminska (2010) the duration of the survey decreases as straightlining increases, bringing to question the quality of the data. The duration of the survey was also checked by Qualtrics. Through the initial launch of the survey, Qualtrics has determined that the median time duration for the survey completion was 7.3 minutes. The software also performed speed check for the rest of the surveys. Those participants that took less than one third of the median time to complete the survey were eliminated for not responding thoroughly. Distribution of surveys sometimes show straight-lining of the responses. Straight-lining is indicated by the selection of the same response option for an entire set of items that are measuring the same construct. If a participant's responses demonstrate straight-lining for too many constructs, then that participant is rejected. This study employed straight-line analysis with the aid of Excel software. Once the analysis was complete, the straight-lined total scores were ranked. From a detailed analysis of responses to the indicators for each question, the majority of 
the participants straightlined six of the ten constructs (personalization, performance expectancy, social influence, privacy concerns, hedonic motivation and price value). This may have happened due to the design of the questionnaire, the wording in the survey or the selection of indicators which were highly correlated. The straightline analysis then focused on the remaining four constructs (intention to use, habit, facilitating conditions and health consciousness). I eliminated those surveys where more than $50 \%$ of these four constructs were straightlined.

\section{Partial Least Squares (PLS)}

The method of statistical analysis used in this study is Partial Least Square (PLS). PLS is also called PLS modeling. PLS is a multivariate analysis that simultaneously analyzes multiple variables (Hair Jr, Hult, Ringle, \& Sarstedt, 2016). It is mostly used in exploratory research to develop theories. It focuses on explaining the variance in the dependent variable when testing the research model (Hair Jr et al., 2016). It also has the ability to handle small sample sizes and does not require normal distributed data (Hair et al., 2014).

PLS is used to confirm a priori established theories (Hair Jr et al., 2016), and to predict and explain target constructs (Rigdon et al., 2014). Additionally, the measurements are obtained from surveys that are used to collect primary data (Hair Jr et al., 2016). PLS is an appropriate approach when predictive accuracy is crucial (Hwang et al., 2010). This statistical method has been used in studies of UTAUT2 and other technology adoption research (Agarwal, Ahuja, Carter, \& Gans, 1998; Davis, 1989; Gao et al., 2015; Venkatesh et al., 2012). Due to the primary objectives of this study to predict variables that influence the intention to use WTDs, the survey method of collecting data, and the a priori nature of the model and the hypotheses, PLS is an 
appropriate method to use in this study. The data analysis was conducted using SmartPLS (Ringle, Wende, \& Becker, 2015).

PLS analysis consists of two parts: the structural model and the measurement model. The structural model shows the relationship between the constructs in the model. In other words, it shows how latent constructs are related to each other, which is the explanatory power of the model. The measurement model shows how the constructs are measured, by analyzing the relationships between the constructs and their indicator variables (Hair Jr et al., 2016).

First, SmartPLS used confirmative factor analysis to evaluate whether the indicators for each question converge on their construct. Then the structural model was tested via the PLS algorithm that calculated path coefficients and $\mathrm{R}^{2}$ for the endogenous variables. The bootstrapping was used to calculate the t-values for this research by setting it to a sample of 5000. Because PLS assumes that the data is not normally distributed, it cannot use parametric significance tests that are used in regression analyses to test significance of coefficients of outer loadings and path coefficients. Instead it uses bootstrapping, which is a nonparametric procedure to test for significance of each coefficient (Hair et al., 2014). It is recommended to use a bootstrapping sample of 5,000 which results in a significantly larger than the number of valid observations in the data set, which in our case was 277. 


\section{RESULTS}

At the close of the survey, a total of 330 completed responses were downloaded from Qualtrics and screened for completion and possible elimination. The screening and validation process with straight-line analysis resulted in a total of 277 usable surveys. This is a sufficient sample size for valid statistical results as the rule of thumb is that the sample size should be 10 times the maximum number of paths leading into one variable. In our model, the maximum number is 9 paths on the variable Intention to Use (ITU). Therefore, our sample size should exceed 90, which it does (Hair Jr et al., 2016). Therefore, the sample size of 277 participants is a valid number for statistical significance via PLS analysis.

\section{Descriptive Statistics}

Descriptive statistics were calculated for the mean (M), standard deviation (SD), minimum and maximum scores to indicate the spread of data within the continuous variables. The demographic results indicated that for gender, the majority of participants were female $(51.62 \%)$, while males accounted for $48.38 \%$ of the total number of participants. See Table 2 .

\begin{tabular}{|l|l|l|}
\hline Gender & Number (n) & Percentage (\%) \\
\hline Male: & 134 & $48.4 \%$ \\
Female: & 143 & $51.6 \%$ \\
\hline Total: & $\mathbf{2 7 7}$ & $\mathbf{1 0 0 \%}$ \\
\hline
\end{tabular}

Table 2: Gender

Age was measured in years $(M=41.78, \mathrm{SD}=14.65)$, with majority of respondents being between ages of 22-40 (49.82\%), identified as Millennials (1977-1995), followed by the age range of 53-71 (21.66\%), identified as Baby Boomers (1946-1964), and 41-52 (20.94\%) identified as Generation X (1965-1977). Minority of the respondents were ages 72-82 (3.61\%), 
identified as Traditionalists (1945-earlier), followed by age range of 18-21 (3.9\%) of Generation Z (1996- later). See Table 3.

\begin{tabular}{|l|l|l|l|}
\hline Generation group & Age group & Number (n) & $\begin{array}{l}\text { Percentage } \\
(\%)\end{array}$ \\
\hline Generation Z (1996-1ater) & $18-21$ & 11 & $3.9 \%$ \\
Millenials (1977-1995) & $22-40$ & 138 & $49.8 \%$ \\
Generation X (1965-1976) & $41-52$ & 58 & $20.9 \%$ \\
Baby Boomers (1946-1964) & $53-71$ & 60 & $21.7 \%$ \\
Traditionalists (1945-Earlier) & $72-82$ & 10 & $3.6 \%$ \\
\hline Total & & 277 & $100.00 \%$ \\
\hline
\end{tabular}

Table 3: Age Group by Generation

Within the variable of educational level, the majority were college graduates $(35.02 \%)$,

followed by university graduates with bachelor degrees $(31.05 \%)$, with less than one quarter

having completed only high school (20.58\%). $11.19 \%$ had postgraduate degrees, and $2.17 \%$ had less than high school. See Table 4.

\begin{tabular}{|l|c|c|}
\hline Level of Education & Number (n) & Percentage (\%) \\
\hline Less than High school & 6 & $2.2 \%$ \\
High School & 57 & $20.6 \%$ \\
Some College & 97 & $35.0 \%$ \\
University Undergraduate & 86 & $31.1 \%$ \\
University Postgraduate & 31 & $11.2 \%$ \\
\hline Total & & $100.00 \%$ \\
\hline
\end{tabular}

Table 4: Level of Education

The majority of participants $(26.7 \%)$ had an annual income between $\$ 30,000$ and $\$ 49,000$, followed by $25.99 \%$ of those with annual income of less than $\$ 30,000$. And $24.5 \%$ of participants had income between $\$ 50,000$ and $\$ 74,999$. See Table 5 for complete results.

\begin{tabular}{|l|c|c|}
\hline Annual Income & Number (n) & Percentage (\%) \\
\hline Less than \$30,000 & 72 & $25.9 \%$ \\
$\$ 30,000-\$ 49,9999$ & 74 & $26.7 \%$ \\
$\$ 50,000-\$ 74,999$ & 68 & $24.5 \%$ \\
$\$ 75,000-\$ 99,9999$ & 28 & $10.1 \%$ \\
$\$ 100,000-\$ 149,999$ & 18 & $6.5 \%$
\end{tabular}




\begin{tabular}{|l|c|c|} 
Over $\$ 150,000$ & 17 & $6.1 \%$ \\
\hline Total & 277 & $100.00 \%$ \\
\hline
\end{tabular}

Table 5: Annual Income

Our sample showed $53.79 \%$ of the participants owned a wearable device, See Table 6.

\begin{tabular}{|l|l|l|}
\hline Own Wearables: & Number & Percentage (\%) \\
\hline Yes & 149 & $53.8 \%$ \\
No & 128 & $46.2 \%$ \\
\hline Total: & 277 & $100.00 \%$ \\
\hline
\end{tabular}

Table 6: Ownership of wearables

Of those participants that owned wearable technology devices, the majority used FitBit (48.30\%), followed by Apple watch (23.86\%), and Samsung gear S2 (11.36\%). The results showed that several participants owned more than one WTD. See Table 7.

\begin{tabular}{|l|c|c|}
\hline Wearable Types: & Number (n) & Percentage \\
\hline Fitbit & 85 & $48.3 \%$ \\
Apple watch & 42 & $23.9 \%$ \\
Samsung gear S2 & 20 & $11.4 \%$ \\
Garmin & 10 & $5.7 \%$ \\
Samsung Gear Fit2 & 5 & $2.8 \%$ \\
Other & 4 & $2.3 \%$ \\
Pebble Time Steel & 4 & $2.3 \%$ \\
Misfit & 3 & $1.7 \%$ \\
Jawbone & 3 & $1.7 \%$ \\
\hline Total & 176 & $100 \%$ \\
\hline
\end{tabular}

Table 7:Wearable types

Just over 50\% of participants had owned this technology for one year or less: 0-6 months (28.9\%), followed by 7 month to 1 year (27.5\%), 27.52\% owned technology 1 to 2 years, and $12.08 \%$ have used the technology for more than a year. See Table 8.

\begin{tabular}{|l|c|c|}
\hline Length of ownership & Number (n) & Percentage (\%) \\
\hline 0-6 months & 43 & $28.9 \%$ \\
7 months to 1 year & 41 & $27.5 \%$ \\
1 year to 2 years & 41 & $27.5 \%$ \\
2 to 3 years & 18 & $12.1 \%$
\end{tabular}




\begin{tabular}{|c|c|c|}
\hline 3 to 4 years & 2 & $1.3 \%$ \\
\hline 4 to 5 years & 1 & $0.7 \%$ \\
\hline more than 5 years & 3 & $2.0 \%$ \\
\hline Total & 149 & $100.00 \%$ \\
\hline
\end{tabular}

The survey provided a list of features that could be used for wearable technology. The most popular feature was to record the number of steps walked during the day, followed by the tracking of fitness activity and calorie burn. See Table 9.

\begin{tabular}{|l|c|}
\hline Function & Rank \\
\hline Record steps I take throughout the day & 1 \\
Track my fitness activities & 2 \\
Count calorie burn & 3 \\
Monitor my heart rate & 4 \\
Track my sleeping pattern & 5 \\
Monitor my health on specific medication & 6 \\
Record my moods & 7 \\
\hline
\end{tabular}

Table 9: Wearable technology features.

\section{Statistical Analysis}

PLS analysis is performed in two steps: the analysis of the measurement model followed by the analysis of the path model (Chin, 2010). The measurement model is first validated for robustness, followed by the evaluation of the structural model to determine support of the research hypotheses (Hair Jr et al., 2016; Jörg Henseler \& Sarstedt, 2013). PLS analysis starts with the evaluation of the measurement model. In this research, the constructs are measured reflectively, where latent constructs connect to the indicator (Hair et al., 2014). This is the dominant specification in management and psychological sciences (Coltman, Devinney, Midgley, \& Venaik, 2008). Reflective measurement is typical of classical test theory and factor analysis (Jarvis, MacKenzie, \& Podsakoff, 2003). The steps for the systematic evaluation of PLS results are shown in Table 10. 


\section{Evaluation of the Reflective Measurement Model}

1) Internal consistency

a) Cronbach's alpha

b) Composite reliability

2) Convergent Validity

a) Indicator reliability

b) Average variance extracted (AVE)

3) Discriminant validity

\section{Evaluation of the Path Model}

1) Coefficients of determinations $\left(R^{\wedge} 2\right)$

2) Predictive relevance $(\mathrm{Q} 2)$

3) Size and significance of path coefficients

4) F2 effect size

Table 10: Systematic Evaluation of PLS Results (Hair Jr et al., 2016)

\section{The Measurement Model}

The structural model was developed based on 28 indicators that were grouped into the nine exogenous latent variables of Performance Expectancy (PE), Facilitating Conditions (FC), Social Influence (SI), Hedonic Motivation (HM), Habit (HB), Price Value (PV), Personalization (PR), Privacy Concerns (PC), Health Consciousness (HC). The endogenous latent variable of Intention to Use (ITU) was measured by 4 indicators.

PLS requires the quality criteria for the path model to achieve appropriate levels of factorial, convergent, discriminant validities and internal consistency reliability. To validate the robustness of the construct and to validate that the indicators of each construct are measuring specific construct, statistical reliability, convergent and discriminant validity were tested.

\section{Outer loadings}

The SmartPLS algorithm calculated the outer loadings for each construct. Outer loadings are associated with results for the reflective measurement model. The measurements are used to evaluate each item's impact to the assigned construct (Hair et al., 2014). Results show that all indicators were convergent, as their correlation coefficients were greater than 0.708 (Jörg 
Henseler \& Sarstedt, 2013). Therefore, all items of each construct are correlated, meaning that the items are measuring the assigned construct. Table 11 shows outer loadings.

\begin{tabular}{|c|c|c|c|c|c|c|c|c|c|c|}
\hline Latent Variable & BI & FC & HB & $\mathrm{HC}$ & HD & PC & PE & PR & $\mathbf{P V}$ & SI \\
\hline BI1 & 0.925 & & & & & & & & & \\
\hline BI2 & 0.963 & & & & & & & & & \\
\hline BI3 & 0.943 & & & & & & & & & \\
\hline BI4 & 0.956 & & & & & & & & & \\
\hline FC1 & & 0.844 & & & & & & & & \\
\hline FC2 & & 0.876 & & & & & & & & \\
\hline FC3 & & 0.748 & & & & & & & & \\
\hline HB1 & & & 0.943 & & & & & & & \\
\hline HB2 & & & 0.959 & & & & & & & \\
\hline HB3 & & & 0.934 & & & & & & & \\
\hline HC1 & & & & 0.817 & & & & & & \\
\hline HC2 & & & & 0.849 & & & & & & \\
\hline HC3 & & & & 0.755 & & & & & & \\
\hline HC4 & & & & 0.750 & & & & & & \\
\hline HC6 & & & & 0.755 & & & & & & \\
\hline HM1 & & & & & 0.956 & & & & & \\
\hline HM2 & & & & & 0.959 & & & & & \\
\hline HM3 & & & & & 0.923 & & & & & \\
\hline PC1 & & & & & & 0.946 & & & & \\
\hline PC2 & & & & & & 0.927 & & & & \\
\hline PC3 & & & & & & 0.903 & & & & \\
\hline PE1 & & & & & & & 0.950 & & & \\
\hline PE2 & & & & & & & 0.949 & & & \\
\hline PE3 & & & & & & & 0.925 & & & \\
\hline PR1 & & & & & & & & 0.918 & & \\
\hline PR2 & & & & & & & & 0.935 & & \\
\hline PR3 & & & & & & & & 0.932 & & \\
\hline PV1 & & & & & & & & & 0.919 & \\
\hline PV2 & & & & & & & & & 0.960 & \\
\hline PV3 & & & & & & & & & 0.968 & \\
\hline SI1 & & & & & & & & & & 0.948 \\
\hline SI2 & & & & & & & & & & 0.965 \\
\hline
\end{tabular}




\begin{tabular}{|l|l|l|l|l|l|l|l|l|l|l|}
\hline S13 & & & & & & & & & & 0.956 \\
\hline
\end{tabular}

Table 11: Outer loadings.

\section{Internal Consistency}

Internal consistency reliability determines whether the items measuring the same construct produce similar results. The internal consistency of the model is measured by Cronbach's alpha. Cronbach's alpha is a widely-used index that measures the reliability of a construct, which assumes that all indicators have equal outer loadings on the construct (Hair Jr et al., 2016; Santos, 1999). The construct is considered reliable if Cronbach's alpha is above 0.70 (Cronbach \& Meehl, 1955). Internal consistency reliability was confirmed by SmartPLS output, where Cronbach's alpha of each latent variable was greater than 0.7. (See Table 12).

Indicators are prioritized by PLS according to their individual predictive validity, and due to Cronbach alpha's sensitivity to the number of items in the scale, it often underestimates the internal consistency (Hair Jr et al., 2016). Therefore, it is recommended to apply an additional and different measure of internal consistency reliability. Composite Reliability is another measure of internal consistency reliability. Different outer loadings of the latent variables of each specific construct are taken into account when measuring for reliability (Bollen, 2011). In order to be considered adequate, measurements should be greater than 0.6 in exploratory research (Hair Jr et al., 2016). Composite reliability for this study was greater than 0.6 (Jorg Henseler, Ringle, \& Sinkovics, 2009). (See Table 12).

Together, the results indicate that the model has good evidence of internal consistency. 


\section{Convergent Validity}

Convergent validity determines if items designed to measure the assigned constructs are indeed measuring that construct. To establish convergent validity of the path model, Average Variance Extracted (AVE) was performed. To obtain AVE scores, each of the outer loadings, of each construct is squared (Hair Jr et al., 2016). In order to confirm convergent validity, AVE scores must be higher than 0.5 (Aldás-Manzano, Ruiz-Mafé, \& Sanz-Blas, 2009; Bagozzi \& Yi, 1988). Value of AVE of 0.5 and above indicates that a particular construct explains more than half of the variance of its items (Hair et al., 2014). The results shown in Table 12 indicate that all latent constructs have AVE greater than 0.5. Therefore, the items of each construct are convergent.

\begin{tabular}{|l|l|l|l|l|l|l|}
\hline $\begin{array}{l}\text { Latent } \\
\text { Variable }\end{array}$ & $\begin{array}{l}\text { Cronbach's } \\
\text { Alpha }\end{array}$ & rho_A & $\begin{array}{l}\text { Composite } \\
\text { Reliability }\end{array}$ & AVE & $\begin{array}{l}\text { R Square } \\
\left(\mathbf{R}^{\wedge} \mathbf{2}\right)\end{array}$ & $\begin{array}{l}\text { Fornell- } \\
\text { Larker } \\
\text { Criterion }\end{array}$ \\
\hline ITU & 0.961 & 0.962 & 0.972 & 0.896 & 0.768 & 0.947 \\
\hline FC & 0.764 & 0.785 & 0.864 & 0.680 & & 0.825 \\
\hline HB & 0.940 & 0.943 & 0.962 & 0.893 & & 0.945 \\
\hline HC & 0.856 & 0.859 & 0.896 & 0.618 & & 0.786 \\
\hline HD & 0.941 & 0.943 & 0.962 & 0.895 & & 0.946 \\
\hline PC & 0.918 & 0.965 & 0.947 & 0.857 & & 0.926 \\
\hline PE & 0.936 & 0.939 & 0.959 & 0.886 & & 0.941 \\
\hline PR & 0.920 & 0.920 & 0.949 & 0.862 & & 0.928 \\
\hline PV & 0.945 & 0.959 & 0.965 & 0.902 & & 0.949 \\
\hline SI & 0.953 & 0.954 & 0.970 & 0.914 & & 0.956 \\
\hline
\end{tabular}

Table 12: PLS Quality Criteria. Construct reliability and Validity.

\section{Discriminant Validity}

Discriminant validity is used to distinguish one construct from other constructs. The criteria for discriminant validity is that the AVE extracted among a set of constructs is higher than the squared correlation between two constructs (Hair Jr et al., 2016). It is determined in 
terms of how each construct correlates with others, and how much the items represent a single construct. One way to establish discriminant validity is to use Fornell-Larcker scores (Fornell \& Larcker, 1981). Fornell-Larcker criterion compares the square root of each construct's AVE with its correlations with all the other constructs (Hair et al., 2014). Table 12 and Table 13 show that the square root of AVE estimates had values between 0.786 and 0.956 , which were greater than the correlation coefficients. In this case, the results indicated that this model has good evidence of discriminant validity. The strongest relationships are with the construct's own indicators, as shown in Table 13

\begin{tabular}{|l|l|l|l|l|l|l|l|l|l|l|}
\hline $\begin{array}{l}\text { Latent } \\
\text { Variables }\end{array}$ & ITU & FC & HB & HC1 & HD & PC & PE & PR & PV & SI \\
\hline ITU & $\mathbf{0 . 9 4 7}$ & & & & & & & & & \\
\hline FC & 0.673 & $\mathbf{0 . 8 2 5}$ & & & & & & & & \\
\hline HB & 0.779 & 0.595 & $\mathbf{0 . 9 4 5}$ & & & & & & & \\
\hline HC1 & 0.261 & 0.236 & 0.225 & $\mathbf{0 . 7 8 6}$ & & & & & & \\
\hline HD & 0.792 & 0.651 & 0.787 & 0.248 & $\mathbf{0 . 9 4 6}$ & & & & & \\
\hline PC & -0.161 & -0.112 & -0.075 & 0.039 & -0.173 & $\mathbf{0 . 9 2 6}$ & & & & \\
\hline PE & 0.701 & 0.493 & 0.667 & 0.397 & 0.698 & -0.129 & $\mathbf{0 . 9 4 1}$ & & & \\
\hline PR & 0.653 & 0.586 & 0.539 & 0.338 & 0.594 & -0.108 & 0.623 & $\mathbf{0 . 9 2 8}$ & & \\
\hline PV & 0.675 & 0.630 & 0.678 & 0.347 & 0.659 & -0.152 & 0.622 & 0.541 & $\mathbf{0 . 9 4 9}$ & \\
\hline SI & 0.698 & 0.542 & 0.679 & 0.216 & 0.627 & -0.078 & 0.571 & 0.467 & 0.648 & $\mathbf{0 . 9 5 6}$ \\
\hline
\end{tabular}

Table 13: Table of Fornell-Larcker Scores.

Overall, composite reliability, Cronbach alpha, AVE, Fornell-Larcker criterion, and outer loadings showed evidence that the measurement model was valid and robust (Fornell \& Larcker, 1981).

\section{Path Model}

The first step in the analysis of the path model is the assessment for collinearity issues. Collinearity arises when two indicators in a multiple regression model are highly correlated (Hair et al., 2014). In other words, with a high degree of accuracy, one variable can be linearly 
predicted from the others. The Variance Inflation Factor (VIF) was used to evaluate the collinearity among the predictor variables. In the context of PLS, a potential problem of collinearity rises when VIF indicate values of 0.20 and lower or values of 5 and higher (Hair, Ringle, \& Sarstedt, 2011). Table 14 shows VIF scores, all of which are within the range.

\begin{tabular}{|c|c|}
\hline Variables & \multicolumn{1}{l|}{ VIF } \\
\hline FC & 2.197 \\
\hline HB & 3.382 \\
\hline HC & 1.267 \\
\hline HD & 3.580 \\
\hline PC & 1.066 \\
\hline PE & 2.666 \\
\hline PR & 2.017 \\
\hline PV & 2.615 \\
\hline SI & 2.185 \\
\hline
\end{tabular}

Table 14: Collinearity Statistics.

The coefficient of determination, denoted as $\mathrm{R}^{2}$, is the most commonly used measurement to evaluate the structural model (Hair et al., 2014). The higher the $\mathrm{R}^{2}$ value of endogenous constructs, the better the construct is explained by the latent variables in the path model. The $\mathrm{R}^{2}$ value ranges between 0 and 1 , where higher levels indicate that more of the variance is explained by the independent variables (Hair et al., 2014). In this research model, the endogenous construct of intention to use (ITU) has a value of $\mathrm{R}^{2}=0.768$, which is considered strong.

Stone - Geisser's $Q^{2}$ value should be measured as a criterion of predictive accuracy (Hair et al., 2014). $Q^{2}$ is an indicator of the model's predictive relevance. Predictive relevance refers to "a synthesis of cross validation and function fitting with the perspective that prediction of observables is of much greater relevance than the estimation of what are often artificial 
construct - parameters" (Geisser, 1975, p. 320). In other words, predictive relevance in PLS path model analysis indicates that it accurately predicts data that is not used in the model estimation. $\mathrm{Q}^{2}$ values were obtained by using blindfolding algorithm that omits every seventh data point for the indicators for the selected endogenous factor and performs seven iterations (Hair Jr et al., 2016). The estimates from these iterations are then combined to calculate a total estimate of the cross-validated redundancy, which is the $\mathrm{Q}^{2}$ measure. $\mathrm{Q}^{2}$ values larger than zero for reflective endogenous latent variables are indicative of the path model relevance for dependent constructs. This study obtained $\mathrm{Q}^{2}$ of 0.637 which is an indicative of a highly predictive relevance for intention to use (ITU). Table 15 shows results for $\mathbf{Q}^{2}$ and $\mathbf{R}^{\mathbf{2}}$.

\begin{tabular}{|l|l|l|}
\hline Predictors & $\mathbf{R}^{\mathbf{2}}$ & $\mathbf{Q}^{\mathbf{2}}$ \\
\hline ITU & $76.8 \%$ & $0.637>0$ \\
\hline
\end{tabular}

Table 15: Results of R2 and Q2.

In addition to evaluating $\mathbf{R}^{\mathbf{2}}$ and $\mathbf{Q}^{\mathbf{2}}$, the effect size of each variable should also be measured. The effect size is measured by $f$ squared $\left(f^{2}\right)$. The effect size $\left(f^{2}\right)$ analyzes the relevance of exogenous constructs in explaining the endogenous construct. Specifically, it analyzes how much a predictor construct (exogenous construct) contributes to the $\mathrm{R}^{2}$ value of the target construct (endogenous construct) in the path model (Hair et al., 2014). It enables assessment of the overall contribution of each latent construct. Each construct is removed from the model and the change in $\mathrm{R}^{2}$ is calculated. The value of $f^{2}$ is:

$f^{2}=\left(\mathrm{R}^{2}\right.$ included $-\mathrm{R}^{2}$ excluded $) / 1-\mathrm{R}^{2}$ included where $R^{2}$ included is for all constructs and $R^{2}$ excluded is when the selected construct is removed from the model. 
As recommended by Hair et al. (2014), the effect size $\left(f^{2}\right)$ is considered small if the value is between 0.02 and 0.14 , medium if it is between 0.15 and 0.34 and large if it is 0.35 and over. In the current model, most of the constructs have a small explanatory power on intention to use. Table 16 shows the effect size.

\begin{tabular}{|c|c|c|c|}
\hline \multicolumn{1}{l|}{ Construct } & Dependent Variable & $\boldsymbol{f}$ & Effect size \\
\hline FC & ITU & 0.037 & Small \\
\hline HB & ITU & 0.069 & Small \\
\hline HD & ITU & 0.061 & Small \\
\hline PE & ITU & 0.022 & Small \\
\hline PR & ITU & 0.049 & Small \\
\hline SI & ITU & 0.066 & Small \\
\hline
\end{tabular}

Table 16: Effect size.

The path diagram with path coefficients $(\beta)$ measures the directions and strengths of the relationships between latent variables, using the scale between -1 and +1 . For each path in the model, the t-values were calculated by bootstrapping with 5000 samples. The mean values of $\beta$ coefficient were computed, and two-tailed t-tests were conducted to determine if the mean values were significantly different from zero at $\mathrm{p}<0.05$ (indicated by $\mathrm{t}>1.96$ ). Three of the independent variables did not have a significant influence on intention to use: these were privacy concerns, perceived value, and health consciousness. All other hypotheses were supported with $\mathrm{p}$ $<0.05$ or $\mathrm{p}<0.001$. Summary of the results are represented in Note: $*_{p<0.05,} \quad{ }^{* *} p<0.01$ Table 17.

\begin{tabular}{|c|c|c|c|c|}
\hline Number & Hypothesis & Original Sample (O) & T Statistics & Supported \\
\hline 1 & PE --> ITU & 0.116 & $1.96^{*}$ & $\checkmark$ \\
\hline 2 & SI --> ITU & 0.182 & $3.63^{* *}$ & $\checkmark$ \\
\hline 3 & FC --> ITU & 0.137 & $2.425^{*}$ & $\checkmark$ \\
\hline 4 & HD $\rightarrow$ ITU & 0.224 & $3.159^{*}$ & $\checkmark$ \\
\hline 5 & HB--> ITU & 0.233 & $3.616^{* *}$ & $\checkmark$ \\
\cline { 2 - 5 } & \multicolumn{2}{|c}{} & &
\end{tabular}




\begin{tabular}{|c|c|c|c|c|}
\hline 6 & PV --> ITU & 0.005 & 0.097 & \\
\hline 7 & PR --> ITU & 0.151 & $3.048 *$ & $\checkmark$ \\
\hline 8 & PC --> ITU & -0.043 & 1.230 & \\
\hline 9 & $\mathrm{HC}-->\mathrm{FC}$ & -0.002 & 0.056 & \\
\hline
\end{tabular}

Table 17: Summary of results.

In the next section research questions and hypotheses will be evaluated in greater detail based on the statistical results from the PLS-SEM analysis with bootstrapping and blindfolding performed on the extended UTAUT2 model. 


\section{DISCUSSION}

The following section discusses the outcomes related to the nine sets of hypotheses formulated for this study. Each of the hypotheses' path coefficients and statistical significance are further interpreted and discussed within the context of this research.

The results from statistical analysis of the data gathered through the collection of survey data showed that the constructs of Performance Expectancy (PE), Facilitating Conditions (FC), Social Influence (SI), Habit (HB), Hedonic Motivation (HM), and Personalization (PR) were positively associated with the intention to use (ITU) of WTDs by consumers in the context of healthcare, while Price Value (PV), Privacy Concern (PC) and Health Consciousness (HC) were not. Therefore, only six out of nine hypotheses were supported in this research. The model explained the relationship between the latent variables and the dependent variable (ITU) and

explained a highly significant $\left(\mathrm{R}^{2}=0.768\right)$ amount of the variance in ITU. The $\mathrm{Q}^{2}$ values for the predictor variables were well above zero, which showed good predictive relevance for the model.

In this section, each of the hypotheses will be summarized along with the findings.

Research question 1: What factors facilitate individuals to change their behavioural intention to use wearable technology devices?

\section{Hypothesis 1: PE positively affects consumer intention to use WTDs}

The estimates from PLS showed a $\mathrm{p}$-score of $\mathrm{p}=0.05$ between performance expectancy and intention to use, which supports hypothesis 1 that PE positively affects consumers' intention to use WTDs. However, PE has a small effect, because results show the path coefficient to be 0.116 and $\underset{f}{\boldsymbol{2}}$ to be 0.022 . These results support the findings of other WTDs studies (Gu et al., 2016; Guo et al., 2015) that PE has a positive effect on behavioural intention to use WTDs. 
New wrist-worn WTDs can not only track physical activity, measure heart rate, distance traveled, calories consumed, or a sleep pattern, but they also offer new kinds of sensors that measure blood glucose and cardiac monitors that can check breathing rate, stress level, and different kinds of brain activity. The new measurements are critical in the use of healthcare. Healthcare providers and consumers can keep track of the heart rate and blood glucose without intrusive procedures. In order to persuade consumers to use WTDs in healthcare, healthcare providers and WTD companies may want to focus on health related functionality that the devices offer. Furthermore, practitioners may wish to emphasize the device's accuracy of collecting health data which can be used to help healthcare providers and consumers to efficiently monitor their health. In other words, the design behind the technology and its application needs to have a clear intent of how the technology can help consumers in the context of healthcare.

Additionally, healthcare providers may suggest that WTDs will give more accurate results if they continuously wear and use the technology, than when patients track their health manually with pen and paper.

\section{Hypothesis 2: Facilitating Conditions positively affect consumer's intention to use}

\section{WTDs}

The estimates from PLS showed a $\mathrm{p}$-score of $\mathrm{p}<0.05$ between Facilitating Conditions and intention to use, which supports hypothesis 2 that FC has a significant effect on consumers' intention to use WTDs. However, FC has a small but significant effect as the results show the path coefficient to be 0.137 and $\underset{\boldsymbol{f}}{\mathbf{2}}$ to be 0.037 .

As previously discussed most wearable devices fail to keep the user engaged in using the technology (Ledger, 2014). However, reinforcing customer service and reassuring that technology support is available for consumers, may provide confidence for the consumers that 
the company's infrastructure is capable of solving problems that may arise with the use of the technology. In the context of healthcare, consumers want to be assured that their healthcare providers will also be able to help them navigate the technology, and easily read and understand the output.

\section{Hypothesis 3: Social Influence positively affects consumer's intention to use WTDs}

The estimates from PLS-SEM showed a $\mathrm{p}$ - score of $\mathrm{p}<0.001$ between social influence and consumer intention to use WTDs, confirming the significance of the construct on behavioural intention with a path coefficient value of 0.182 and $\underset{f}{\mathbf{2}}=0.066$, and therefore supporting hypothesis 3 .

These results suggest that social influence should be considered when investigating acceptance of technology in healthcare context. This confirms that people might be influenced by others within their social circle, such as family members and friends. Social influence may affect user behaviour on a greater scale.

Social connections could be a powerful source of motivating users to sustain their engagement with WTDs. According to the Cognitive Neuroscience research lab at UCLA, connecting socially with others is as fundamental as the human need for food, water and shelter

(Lieberman, 2013). Therefore, companies need to pay attention to the social aspect of technology when considering incorporating WTDs into healthcare. For example, if a patient downloads a mobile app to use together with WTDs to monitor their health condition (e.g., Parkinson disease, diabetes, etc) there should be a way to connect users with the same health concerns and health needs via social networks. Hence the WTD enables a social platform that allows users to share thoughts, results and interact with users of similar needs, interests and/or health issues. 


\section{Hypothesis 4: Hedonic motivation positively influence consumers' intention to use}

\section{WTDs}

The estimates from PLS showed a $\mathrm{p}$ - score of $\mathrm{p}<0.05$ between social influence and consumer intention to use WTDs, confirming the significance of the construct on behavioural intention with path coefficient's value of 0.224 and $\underset{f}{\mathbf{2}}=0.061$, therefore supporting hypothesis 4.

This finding is consistent with other studies that hedonic motivation has an influence on behavioural intention of adopting a fitness wearable device (Gao et al., 2015; L. H. Wu et al., 2016). Also, this is consistent with our prediction, that users pay more attention to hedonic motivation when they make their decision to use the technology. Therefore, it is important to find what current users of WTDs find most enjoyable about their use of the technology to facilitate further use of the technology and incorporate findings into future marketing campaign.

\section{Hypothesis 5: Habit positively influences consumers' intention to use WTDs}

The estimates from the PLS structural model showed a p-score of $p<0.001$ between habit and intention to use, which supports hypothesis 5 that habit positively affects consumers' intention to use WTDs $(\beta=0.233, \underset{\boldsymbol{f}}{\mathbf{2}}=0.069)$.

This construct has not been tested previously in the context of WTDs. The findings of this study confirm that of other technology adoption studies that there is a significant relationship between habit and intention to use a technology. Wearable devices can facilitate the process of formation of a habit by "directly addressing the element of habit loop" (Ledger, 2014), which in turn could establish a new positive habit (e.g., more exercising). In the past, research shows that re-branding of an exercise could enhance the over all health of a person, for example, studies suggest that it is far more effective to promote prolonged participation, rather than fitness alone 
(Segar, Eccles, \& Richardson, 2011). Therefore, practitioners may wish to find a new marketing strategy to help consumers see the product as a health wellness technology to help them maintain a healthy lifestyle.

\section{Hypothesis 6: Price value positively influences consumers' intention to use WTDs}

The estimates from the PLS structural model showed p-value of 0.923 between PV and intention to use. Based on these findings, it was concluded that PV is not significantly associated with intention to use ( $p>0.05)$. This hypothesis was not supported.

$\mathrm{PV}$ is a cost/benefit analysis which consumers go through in order to determine if they want to use the technology (Venkatesh et al., 2012). I predicted that if consumers assess WTDs as expensive, they may be reluctant to purchasing and using them for health purposes, but as the consumer assessment goes further and identifies a tradeoff between the monetary value and the perceived benefit of using the application, they are more likely to use the technology. The price value is positive when the benefits of using a technology are perceived to be higher than the cost. However, our results show that price value has no significant effect on intention to use the technology.

I predicted for this study that if individuals must spend a significant amount of money for the service they might be reluctant to use WTDs. According to a Colloquy 2016, which surveyed 1,600 American consumers, more than $60 \%$ of consumers think that WTDs are too expensive (Colloquy, 2016). The survey also showed 52\% of participants do not understand the value of wearing these devices. A medical study of patients with type 2 diabetes, who were selfmonitoring their blood-glucose, showed that these patients did not benefit from increased control of glycaemia, but rather the participants found the experience to be intrusive (O'kane, Bunting, 
Copeland, \& Coates, 2008). Therefore, consumers may find it difficult to identify the potential benefit to their health when using WTDs.

This research showed that HD and SI were significant. Perhaps consumers identify WTDs as more of a "fun" and social technology rather than an application that has a potential to save their lives. Practitioners may wish to strongly reinforce to consumers and patients the different health applications that can be used with WTDs.

This construct is also difficult to assess as some of the consumers within this study, have yet to purchase the technology. Therefore, future research could be conducted to compare participants of those that own WTDs to those that do not own WTDs.

The results suggested insights on the effects of the six constructs of the UTAUT2 on the use of WTDs. The study shows that five out of the six constructs relevant to this research question affected consumer intention to use WTDs. Performance expectancy (PE), Social Influence (SI), Facilitating Conditions (FC), Hedonistic motivation (HM), and Habit (HB) all positively affect consumers' behavioural intentions, while Price Value (PV) did not.

Research question 2: Are consumers reluctant to share personal data collected on their WTDs, even when it provides greater personalization?

In order to answer this question, two hypotheses (Hypothesis $7 \& 8$ ) were developed and tested using Personalization-privacy paradox.

\section{Hypothesis 7: Personalization positively influences consumers' intention to use} WTDs

The estimates from PLS showed a p-score of $\mathrm{p}<0.05$ between personalization expectancy 
and intention to use, which supports hypothesis 7 that PR does influence consumers' intention to use WTDs $(\beta=0.151, \stackrel{2}{f}=0.049)$.

WTD users receive personalized, real-time and goal - oriented feedback based on the data that they collect. For example, individuals that previously suffered a heart attack or those that use WTDs to record their vital signs to manage their disease expect reliable information based on their personal data. Personalization might be a factor for consumers who identify themselves as the quantified -self (QS) and use personalized feedback to better monitor their health. Healthcare providers might be successful in identifying these individuals and could recommend health apps based on their health needs. The finding also suggests that in order to convert potential customers into dedicated users, providers may want to extend their efforts into the personalization services catering to specific preferences or habits.

\section{Hypothesis 8: Privacy concerns negatively influence consumers' intention to use}

\section{WTDs}

The estimates from the PLS structural model showed p-value of 0.219 between PC and intention to use. Based on these findings, it was concluded that PC is not significantly associated with intention to use ( $>>0.05)$. This hypothesis was not supported. This result is different from other prior studies of HIT that showed that privacy concerns negatively influenced behavioural intent (Chellappa \& Sin, 2005; Gao et al., 2015; Guo et al., 2015; X. Guo et al., 2012; Sun et al., 2013). This indicates that generally people are not concerned about privacy when they use WTDs. One possible explanation is that consumers already share their personal health information on the Internet via social networks. Thus, there is a minimal concern about the exposure of this private information. In the context of healthcare, consumers use WTDs in order 
to share collected health data with healthcare providers. Furthermore, ResearchKit and CareKit collect health data for further assessment of wearable devices in order to use collected health data and improve future functionality. Users of WTDs often do not actually "own” their health data. Instead the data is collected and stored by the WTD's manufacturer (Piwek et al., 2016). Users are only provided with the personalized results which are extracted from the collected data. In other words, users own the device, but not their data. Today, consumers are reassured by the "anonymity" of the data being collected and perhaps they are willing to give up their privacy to be able to receive personalized results. Privacy is unlikely to be a problem for users of WTDs.

Perceived personalization was found to be positively related to intention to use and negative privacy concerns were not found to be significant in the consumers' intention to use WTD. Therefore, there was no correlation to provide evidence that the privacy - personalization paradox exists in consumers' use of WTDs in the context of healthcare.

Research question 3: Does health consciousness in consumers facilitate intention to use wearable technology devices? In order to answer this question, hypothesis 9 was developed and tested using a health consciousness construct.

\section{Hypothesis 9: Health Consciousness positively affects consumer's intention to use}

\section{WTDs}

The estimates from the PLS structural model showed p-value of 0.955 between HC and intention to use. Based on these findings, it was concluded that $\mathrm{HC}$ is not significantly associated with intention to use $(\mathrm{p}>0.05)$. This hypothesis was not supported. 
Contrary to the hypothesis, health consciousness has no direct effect on the intention to use WTDs. Hypothesis 9 predicted that because there is a significant rise in purchasing of wearable devices consumers are becoming more health conscious and therefore use WTDs to monitor their health and fitness activity. The evidence shows that health consciousness is not an influencing factor. Perhaps individuals are skeptical of health information presented on WTDs and mobile apps. While wearables are improving how they measure our health with sensor devices such as accelerometers, oximeters, gyroscopes and electodermal sensors, the issue of how these devices actually interpret the results and the credibility of this technology should be addressed before these devices are considered to be incorporated into healthcare (CitizenLab, 2016; Piwek et al., 2016). Recently there has been a number of publications in the press about the credibility and effectiveness of the wearable technology (CitizenLab, 2016). For example, some of the devices cannot differentiate if a user is lifting weights or lifting their arm to feed themselves, due to the similar physical motion. When comparing measurements from different WTDs, the results showed a large variation in the accuracy of physical activity measurements with margins of error of up to $25 \%$ (Case, Burwick, Volpp, \& Patel, 2015). Therefore, individuals may still need to take into account other factors, such as the credibility or functionality before they decide to use WTDs to monitor their health.

\section{Theoretical Implications}

This research contributes to the current health information technology acceptance literature by integrating technology acceptance and health behaviour theories. While acceptance of technology has been studied with extant research of healthcare, this study has been one of the first to include habit as a construct of the UTAUT2 model, together with privacy - 
personalization paradox and health consciousness in the context of WTDs. This study adds to the body of literature in the IT-healthcare area of factors that affect consumers' use of technology.

\section{Implications for Practitioners}

Practitioners would find that the results of this research provide some insights for wearable technology and could help them attract more potential customers. WTD providers in the context of healthcare are advised to focus on advertising personalized services to customers according to their preferences, health needs and interests. Privacy is not a concern for consumers, possibly due to the fact that consumers post their private health data on the Internet themselves.

WTD providers should work together with authorized healthcare providers to further the reputation that WTD use and services are endorsed by experts. In addition, service providers should also carry out promotional strategies to obtain potential users by emphasizing the credible function and efficiency of the WTDs services.

As this research identified hedonic motivation and social influence to be significant factors in behavioural intention to use WTDs, it is suggested to create several social platforms to allow consumers to virtually connect with their friends or with other consumers with the same preferences, interests or health concerns. This would enhance enjoyment and increase engagement with WTDs.

Recent gamification of the fitness bracelet has proved to be successful in sustained consumer use of the devices. Gamification is describes as "the use of game design elements in non-game contexts" (Deterding, Dixon, Khaled, \& Nacke, 2011). Gamification, combines social networking services and games. Social networks provide motivational affordance addressing social interactions, which are essential for human beings, while games have shown to provide 
persuasive designs that raise cognitive intrinsic motivations (Hamari, Koivisto, \& Sarsa, 2014). Together, they drive user engagement with an application or IT, making it more enjoyable to use. However, combining social gaming, such as exercise competing and social platforms where users can communicate with one another based on similar health needs should drive users to continued use of WTDs because it addresses fundamental human need for social interactions, as well as it makes the technology "fun" to use.

Therefore, it is important for practitioners to combine the social aspect of gamification with social platforms so that consumers are able to not only compete against each other, but also communicate with other users with similar health needs and their healthcare providers.

\section{Limitations}

As with any study, there were several limitations. One of the limitations is that the study was non-experimental in nature, which means that variables were not manipulated. The study examined the predictive relationships of performance expectancy (PE), social influence (SI), facilitating conditions (FC), habit (HB), hedonic motivation (HD), price value (PV), personalization (PR), privacy concerns (PC), health consciousness (HC), and intention to use (ITU). This type of research cannot be used to imply the cause and effect relationship between these variables. As social influence (SI) and habit (HB) were the most significant constructs, there is a potential for future study in understanding human behaviour in health technology adoption.

Due to the limited budget and time constraints for this study, this study used crosssectional design. The collection of data was done at a single point in time. 
The use of third-party research firms such as Qualtrics who recruit participants may also have limited this study's findings. This research used the services of a professional research organization that recruits individuals who like to respond to survey questionnaires in return for a monetary reward. This does not represent a general population. It is also uncertain how many participants truthfully and accurately answered the questions.

Due to straightline analysis, I acknowledge the likelihood of excluding good data in this analysis. Participants could have answered all the questions correctly, but they may have still straightlined their answers. However, it is also possible that I included bad data in the analysis as well, perhaps participants may have randomly answered questions and tried not to give straightlined answers.

A further limitation is that the survey was only sent to consumers in United States of America and therefore reflects their experience with the technology. It excludes the opinions of Canadian and Mexican markets, which would be a greater representation of North American markets. This research did not consider the potential influence of technology adoption among different cultures. Hence, testing whether the provided relationships are still valid in other countries is necessary. Future researchers could extend this study by conducting a comparison of consumer acceptance between different cultures of different countries.

\section{FUTURE RESEARCH}

In the future, researchers should extend the study by utilizing a longitudinal approach. Future studies could test age, gender, and usage as moderators in order to determine their influence on intention to use WTDs. Additionally, with more time, semi-structured interviews would allow for more insights via qualitative analysis. Furthermore, more analytical techniques 
could be applied to the data. Future researchers should also utilize a broader sampling and could expand through a refined sampling design. For example, future studies could research specific types of WTDs, such as smartwatches or fitness wristbands.

This study was not able to provide evidence that health consciousness significantly affects consumer's intention to use WTDs. However, I suggest that there are other factors that may influence consumers to use the technology beyond health concerns. Because social influence was the strongest construct, we suggest the addition of the construct of 'social image'. The social image construct is derived from innovation diffusion theory, and refers to respect and admiration that one expects to gain from one's peers as a result of one's behaviour (Lu, Yu, Liu, \& Yao, 2003). Researchers could compare the influence of users' social image to their concerns about their health.

Additionally, health consciousness and privacy concerns may be used as moderators in future studies of adoption of WTDs. Moreover, this study only addressed behavioural intention to use WTDs rather than the continuous usage of WTDs. Thus, Continuance Behaviour (Bhattacherjee, Perols, \& Sanford, 2008) could be considered in order to test consumers' intentions to continuously use WTDs in the future.

Finally, this study included privacy - personalization paradox factors as independent variables that affect consumers' intention to use WTDs. Future research could examine trust as a mediator between privacy - personalization paradox and behavioural intention to use WTDs in the context of healthcare. 


\section{CONCLUSION}

As the adoption of wearable technology devices is increasing, so does the abandonment of these devices. There is an increased number of health-conscious people that digitize their health metrics with the use of technology in order to monitor their heath. Today, software platforms, such as Apple's CareKit, are trying to close the gap between everyday wearables and the use of wearables in healthcare. This study provides an understanding of consumers' intentions to use wearable technology in a healthcare setting.

This research was a quantitative, non-experimental, survey based study that examined factors that affect consumers' intentions to use WTDs. This study has contributed to the evaluation of an extension UTAUT2 with the privacy-personalization paradox and health consciousness, within a specific context, namely the use of WTDs in healthcare. From a survey of 277 participants, the results indicate that in the current wearable device market, users are more affected by performance expectancy (PE), social influence (SI), facilitating conditions (FC), habit (HB), hedonic motivation (HD), and personalization (PR) in their intention to use (ITU) WTDs, while price Value (PV), Privacy concerns (PC), and health consciousness were not significant. This approach is applicable to adoption and intent to use of other health information technologies with appropriate suggestions that future researchers conduct a study to compare the impact of different cultures on the adoption of WTDs.

For researchers, this study provides evidence that UTAUT2 is a valuable tool for understanding and explaining why individuals may or may not have the intention to use WTDs in the context of healthcare. This study also shows that the privacy-personalization paradox is not significant in wearable technology, most likely because users post their health information 
online anyway. Finally, health consciousness may not be a significant factor in consumers' intentions to use WTDs.

Practitioners should ensure they prioritize personalized services based on different needs of users, and incorporate social aspects for the promotion of WTDs. Consumers also highly value the opinion of others, and perhaps look to their online social networks or their healthcare providers for further advice. 


\section{APPENDIX}

\section{Questionnaire}

Performance Expectancy (PE) adapted from (Venkatesh et al., 2003)

PE1: Is useful in my daily life to monitor my health

PE2: Improves the quality of my daily healthcare seeking

PE3: Enables me to check on my health more easily

Social Influence (SI) adapted from (Venkatesh et al., 2003)

SI1: People who influence my behaviour think that I should use a wearable device

SI2: People who are important to me think I should use a wearable device.

SI3: Those people whose opinion I value would prefer I use a wearable device

Facilitating Conditions (FC) adapted from (Venkatesh et al., 2003)

FC1: I have the resources necessary to use a wearable device

FC2: A wearable device is compatible with other technologies that I use

FC3: I can get help from others when I have difficulties using a wearable device

Price Value (PV) adapted from (Venkatesh et al., 2012)

PV1: I think wearable devices are reasonably priced.

PV2: I consider wearable devices to be good value for the money

PV3: At the current price, wearable devices provide good value

Habit (HB) adapted from (Venkatesh et al., 2012)

HB1: The use of a wearable device has become a habit for me.

HB2: I am addicted to using a wearable device.

HB3: I must use a wearable device

Hedonic Motivation adapted from (HD) (Venkatesh et al., 2012)

HD1: Using a wearable device is fun

HD2: Using a wearable device is enjoyable.

HD3: Using a wearable device is entertaining

Personalization (PR) (Guo et al., 2015; Komiak \& Benbasat, 2006)

PR1: Can provide me with personalized health services tailored to my needs

PR2: Can provide me with health information tailored to what I want

PR3: Customizes my health information to my needs

Privacy Concerns (PC) adapted from (Featherman \& Pavlou, 2003; Guo et al., 2015)

PC1: I would lose control over the privacy of my information

PC2: My personal information could be used without my knowledge.

PC3: Others might take control of my personal information.

Intention to Use (ITU) adapted from (Johnston \& Warkentin, 2010; Venkatesh et al., 2012)

ITU1: I expect my use of the wearable technology to increase in the future 
ITU2: I intend to use the wearable technology device in the future ITU3: I will always try to use the wearable technology device ITU4: I plan to use the wearable technology device frequently

Health Consciousness adapted from (Dutta-Bergman, 2004; Gould, 1989)

$\mathrm{HC1}$ : I reflect about my health a lot

HC2: I am very self-conscious about my health

HC3: I am alert to changes in my health

HC4: I am usually aware of my health

HC5: I take responsibility for the state of my health

HC6: I am aware of the state of my health as I go through the day

HC7: My heath depends on how well I take care of myself

HC8: I am doing relatively well in taking care of my health 


\section{BIBLIOGRAPHY}

Abril, E. P. (2016). Tracking Myself: Assessing the Contribution of Mobile Technologies for Self-Trackers of Weight, Diet, or Exercise. Journal of Health Communication, 21(6), 638-646.

Accenture. (2015). Enhancing Clinical Practice with Wearables. Retrieved from https://www.accenture.com/t20160519T051015_w_/ca-en/_acnmedia/PDF19/Accenture-Wearables-Health-PoV.pdf - zoom $=50$

Agarwal, R., Ahuja, M., Carter, P., \& Gans, M. (1998). Early and late adopters of IT innovations: extensions to innovation diffusion theory.

Agarwal, R., \& Karahanna, E. (2000). Time flies when you're having fun: Cognitive absorption and beliefs about information technology usage. Mis Quarterly, 24(4), 665.

Aguirre, E., Roggeveen, A. L., Grewal, D., \& Wetzels, M. (2016). The personalization-privacy paradox: implications for new media. Journal of Consumer Marketing, 33(2), 98-110. doi:10.1108/JCM-06-2015-1458

Ajzen, I. (1991). The Theory of Planned Behavior. Organizational Behavior and Human Decision Processes, 50(2), 179.

Albashrawi, M., \& Motiwalla, L. (2015). The Moderating Effect of Privacy and Personalization in Mobile Banking: A Structural Equation Modeling Analysis.

Aldás-Manzano, J., Ruiz-Mafé, C., \& Sanz-Blas, S. (2009). Exploring individual personality factors as drivers of M-shopping acceptance. Industrial Management \& Data Systems, 109(6), 739-757. doi:10.1108/02635570910968018

Alwahaishi, S., \& Snásel, V. (2013). Acceptance and use of information and communications technology: a UTAUT and flow based theoretical model. Journal of Technology Management \& Innovation, 8(2), 61-73.

Anderson, J. E., Schwager, P. H., \& Kerns, R. L. (2006). The Drivers for Acceptance of Tablet PCs by Faculty in a College of Business. Journal of Information Systems Education, 17(4), 429.

Andrews, D., Nonnecke, B., \& Preece, J. (2003). Electronic survey methodology: A case study in reaching hard-to-involve Internet users. International Journal of Human-Computer Interaction, 16(2), 185-210.

Angst, C. M., \& Agarwal, R. (2009). Adoption Of Electronic Health Records In The Presence Of Privacy Concerns: The Elaboration Likelihood Model And Individual Persuasion. Mis Quarterly, 33(2), 339-370.

Apple. (2014). Apple Announces Apple Pay. Retrieved from http://www.apple.com/pr/library/2014/09/09Apple-Announces-Apple-Pay.html

Arenas-Gaitan, J., \& Peral-Peral, B. R.-J., Maria Angeles. (2015). Elderly and internet banking: an application of UTAUT2. The Journal of Internet Banking and Commerce, 2015.

Awad, N. F., \& Krishnan, M. S. (2006). The personalization privacy paradox: an empirical evaluation of information transparency and the willingness to be profiled online for personalization. Mis Quarterly, 13-28.

Bagozzi, R. P., \& Yi, Y. (1988). On the evaluation of structural equation models. Journal of the Academy of Marketing Science, 16(1), 74-94.

Bandura, A. (1977). Self-efficacy - toward a unifying theory of behavioral change. Psychological Review, 84(2), 191-215. 
Baptista, G., \& Oliveira, T. (2015). Understanding mobile banking: The unified theory of acceptance and use of technology combined with cultural moderators. Computers in Human Behavior, 50, 418-430.

Bauer, H. H., Reichardt, T., Barnes, S. J., \& Neumann, M. M. (2005). Driving consumer acceptance of mobile marketing: A theoretical framework and empirical study. Journal of Electronic Commerce Research, 6(3), 181.

BCC Research. (2016). Wearable Computing: Technologies, Applications and Global Markets. Retrieved from http://www.reportlinker.com/p02042684-summary/Wearable-ComputingTechnologies-Applications-and-Global-Markets.html

Bhaskar, R. (1975). A realist theory of science. York: Books.

Bhattacherjee, A., Perols, J., \& Sanford, C. (2008). Information Technology Continuance: A Theoretic Extension and Empirical Test. Journal of Computer Information Systems, 49(1), 17-26.

Bollen, K. A. (2011). Evaluating Effect, Composite, And Causal Indicators In Structural Equation Models. Mis Quarterly, 35(2), 359-372.

Braunsberger, K., Wybenga, H., \& Gates, R. (2007). A comparison of reliability between telephone and web-based surveys. Journal of Business Research, 60(7), 758-764.

Brown, S. A., \& Venkatesh, V. (2005). Model Of Adoption Of Technology In Households: A Baseline Model Test And Extension Incorporating Household Life Cycle. Mis Quarterly, 29(3), 399.

Brown, S. A. D. (2010). Predicting Collaboration Technology Use: Integrating Technology Adoption and Collaboration Research. Journal of Management Information Systems, 27(2), 9-53.

Burrell, G., \& Morgan, G. (1979). Sociological paradigms and organisational analysis : elements of the sociology of corporate life. London: Heinemann.

BusinessInsider. (2016). The global market for IoT healthcare tech will top \$400 billion in 2022. Retrieved from http://www.businessinsider.com/the-global-market-for-iot-healthcaretech-will-top-400-billion-in-2022-2016-5

Canhoto, A. I., \& Arp, S. (2016). Exploring the factors that support adoption and sustained use of health and fitness wearables. Journal of Marketing Management, 1-29.

Case, M. A., Burwick, H. A., Volpp, K. G., \& Patel, M. S. (2015). Accuracy of smartphone applications and wearable devices for tracking physical activity data. JAMA, 313(6), 625626.

CBCnews. (2016). New Apple CareKit health apps help users manage medical conditions. Retrieved from http://www.cbc.ca/news/technology/apple-carekit-1.3557633

Chau, P. Y. K., \& Hu, P. J. H. (2001). Information technology acceptance by individual professionals: A model comparison approach. Decision Sciences, 32(4), 699-719.

Chellappa, R. K., \& Sin, R. G. (2005). Personalization versus privacy: An empirical examination of the online consumer's dilemma. Information Technology and Management, 6(2-3), 181-202.

Chen, C., Zhang, K. Z., \& Zhao, S. J. (2015). Examining the Effects of Perceived Enjoyment and Habit on Smartphone Addiction: The Role of User Type E-Technologies (pp. 224-235): Springer.

Cheung, C. M., Xiao, B., \& Liu, I. L. (2012). The impact of observational learning and electronic word of mouth on consumer purchase decisions: the moderating role of 
consumer expertise and consumer involvement. Paper presented at the System Science (HICSS), 2012 45th Hawaii International Conference on System Sciences.

Chin, W. W. (2010). How to write up and report PLS analyses Handbook of partial least squares (pp. 655-690): Springer.

Cho, H., Rivera-Sánchez, M., \& Lim, S. S. (2009). A multinational study on online privacy: global concerns and local responses. New media \& society, 11(3), 395-416.

Cho, J., Park, D., \& Lee, H. E. (2014). Cognitive factors of using health apps: systematic analysis of relationships among health consciousness, health information orientation, eHealth literacy, and health app use efficacy. Journal of Medical Internet Research, $16(5), \mathrm{e} 125$.

Choe, E. K., Lee, N. B., Lee, B., Pratt, W., \& Kientz, J. A. (2014). Understanding quantifiedselfers' practices in collecting and exploring personal data. Paper presented at the Proceedings of the 32nd annual ACM conference on Human factors in computing systems.

CitizenLab. (2016). Every Step You Fake: A Comparative Analysis of Fitness Tracker Privacy and Security. Retrieved from https://citizenlab.org/2016/02/security-privacy-issuesseveral-leading-wearable-fitness-tracking-devices/

Colloquy. (2016). Passing Fad or Cool Nerdy: Colloquy Research shows 63\% of U.S. Consumers Wary of Wearable Prices.

Coltman, T., Devinney, T. M., Midgley, D. F., \& Venaik, S. (2008). Formative versus reflective measurement models: Two applications of formative measurement. Journal of Business Research, 61(12), 1250-1262. doi:10.1016/j.jbusres.2008.01.013

Compeau, D. R., \& Higgins, C. A. (1995). Computer self-efficacy: Development of a measure and initial test. Mis Quarterly, 19(2), 189.

Compeau, D. R., Higgins, C. A., \& Huff, S. (1999). Social cognitive theory and individual reactions to computing technology: A longitudinal study. Mis Quarterly, 23(2), 145.

Creswell, J. W. (2013). Research design: Qualitative, quantitative, and mixed methods approaches: Sage publications.

Cronbach, L. J., \& Meehl, P. E. (1955). Construct validity in psychological tests. Psychological Bulletin, 52(4), 281-302.

Davis, F. D. (1989). Perceived Usefulness, Perceived Ease Of Use, And User Acceptance. Mis Quarterly, 13(3), 319-340.

Davis, F. D., Bagozzi, R. P., \& Warshaw, P. R. (1992). Extrinsic and Intrinsic Motivation to Use Computers in the Workplace. Journal of Applied Social Psychology, 22(14).

Deterding, S., Dixon, D., Khaled, R., \& Nacke, L. (2011). From game design elements to gamefulness: defining gamification. Paper presented at the Proceedings of the 15th international academic MindTrek conference: Envisioning future media environments.

Dhar, S., \& Varshney, U. (2011). Challenges and business models for mobile location-based services and advertising. Communications of the Acm, 54(5), 121-128.

Dinev, T., \& Hart, P. (2004a). Internet privacy concerns and their antecedents - measurement validity and a regression model. Behaviour \& Information Technology, 23(6), 413-422. doi:10.1080/01449290410001715723

Dinev, T., \& Hart, P. (2004b). Internet privacy concerns and their antecedents-measurement validity and a regression model. Behaviour \& Information Technology, 23(6), 413-422. 
Dodds, W. B., Monroe, K. B., \& Grewal, D. (1991). Effects of Price, Brand, and Store Information on Buyers' Product Evaluations. Journal of Marketing Research (JMR), 28(3).

Dutta-Bergman, M. J. (2004). Primary sources of health information: Comparisons in the domain of health attitudes, health cognitions, and health behaviors. Health communication, 16(3), 273-288.

Dutta-Bergman, M. J. (2005). Developing a profile of consumer intention to seek out additional information beyond a doctor: The role of communicative and motivation variables. Health communication, 17(1), 1-16.

Dwivedi, Y. K., Rana, N. P., Chen, H., \& Williams, M. D. (2011). A Meta-analysis of the Unified Theory of Acceptance and Use of Technology (UTAUT) Governance and Sustainability in Information Systems. Managing the Transfer and Diffusion of IT (pp. 155-170): Springer.

Fang, Y.-M., \& Chang, C.-C. (2016). Users' psychological perception and perceived readability of wearable devices for elderly people. Behaviour \& Information Technology, 35(3), 225232.

FDA. (2017). Digital Health. Retrieved from https://www.fda.gov/medicaldevices/digitalhealth/

Featherman, M. S., \& Pavlou, P. A. (2003). Predicting e-services adoption: a perceived risk facets perspective. International Journal of Human-Computer Studies, 59(4), 451-474.

Field, A. (2013). Discovering Statistics Using IBM SPSS Statistics (M. Carmichael Ed. Vol. 4th Edition). California: SAGE Publications Inc.

Fishbein, M., \& Ajzen, I. (1976). Belief, Attitude, Intention and Behaviour: An Introduction to Theory and Research: Addison-Wesley, Reading, MA.

FitBit. (2017). What should I know about challenges? Retrieved from https://help.fitbit.com/articles/en_US/Help_article/1531

Fornell, C., \& Larcker, D. F. (1981). Evaluating structural equation models with unobservable variables and measurement error. Journal of Marketing Research, 39-50.

FTC Staff Report. (2015). Internet of Things. Privacy and Security in a Connected World. . Retrieved from https://www.ftc.gov/system/files/documents/reports/federal-tradecommission-staff-report-november-2013-workshop-entitled-internet-thingsprivacy/150127iotrpt.pdf

Gao, Y., Li, H., \& Luo, Y. (2015). An empirical study of wearable technology acceptance in healthcare. Industrial Management \& Data Systems, 115(9), 1704-1723. doi:10.1108/IMDS-03-2015-0087

Gardner, B., \& Tang, V. (2014). Reflecting on non-reflective action: An exploratory think-aloud study of self-report habit measures. British Journal of Health Psychology, 19(2), 258273. doi:10.1111/bjhp. 12060

Geisser, S. (1975). The predictive sample reuse method with applications. Journal of the American Statistical Association, 70(350), 320-328.

Goh, J. P. L. (2015). Privacy, Security, and Wearable Technology. Published in Landslide, 8(2).

Gould, S. J. (1989). Health consciousness and health behavior: the application of a new health consciousness scale. American Journal of Preventive Medicine, 6(4), 228-237.

Greenlaw, C., \& Brown-Welty, S. (2009). A comparison of web-based and paper-based survey methods: testing assumptions of survey mode and response cost. Evaluation Review, 33(5), 464-480. 
Groves, R. M., Fowler Jr, F. J., Couper, M. P., Lepkowski, J. M., Singer, E., \& Tourangeau, R. (2011). Survey methodology (Vol. 561): John Wiley \& Sons.

Gu, Z., Wei, J., \& Xu, F. (2016). An Empirical Study on Factors Influencing Consumers' Initial Trust in Wearable Commerce. Journal of Computer Information Systems, 56(1), 79-85.

Guo, \& Poole, M. (2009). Antecedents of flow in online shopping: a test of alternative models. Information Systems Journal, 19(4), 369-390.

Guo, Zhang, X., \& Sun, Y. (2015). The privacy-personalization paradox in mHealth services acceptance of different age groups. Electronic Commerce Research and Applications.

Guo, X., Sun, Y., Yan, Z., \& Wang, N. (2012, 2012). Privacy-Personalization Paradox in Adoption of Mobile Health Service: The Mediating Role of Trust.

Hair, J. F., Hult, G. T. M., Ringle, C. M., \& Sarstedt, M. (2014). A Primer on Partial Least Squares Structural Equations Modeling (PLS-SEM): SAGE Publications.

Hair, J. F., Ringle, C. M., \& Sarstedt, M. (2011). PLS-SEM: Indeed a silver bullet. The Journal of Marketing Theory and Practice, 19(2), 139-152.

Hair Jr, J. F., Hult, G. T. M., Ringle, C., \& Sarstedt, M. (2016). A primer on partial least squares structural equation modeling (PLS-SEM): Sage Publications.

Hamari, J., Koivisto, J., \& Sarsa, H. (2014, 2014). Does Gamification Work? -- A Literature Review of Empirical Studies on Gamification.

Harrington, J., Schramm, P. J., Davies, C. R., \& Lee-Chiong Jr, T. L. (2013). An electrocardiogram-based analysis evaluating sleep quality in patients with obstructive sleep apnea. Sleep and Breathing, 17(3), 1071-1078.

HealthTap. (2017). HealthTap is the world's first Global Health Practice. Retrieved from https://www.healthtap.com/what_we_make/overview

Henseler, J., Ringle, C. M., \& Sinkovics, R. R. (2009). The use of partial least squares path modeling in international marketing. Advances in International Marketing, 20, 277-319.

Henseler, J., \& Sarstedt, M. (2013). Goodness-of-fit indices for partial least squares path modeling. Computational Statistics, 1-16.

Ho, S. Y. (2012). The effects of location personalization on individuals' intention to use mobile services. Decision Support Systems, 53(4), 802-812.

Holden, R. J., \& Karsh, B. T. (2010). The Technology Acceptance Model: Its past and its future in health care. Journal of Biomedical Informatics, 43(1), 159-172. doi:10.1016/j.jbi.2009.07.002

Hong, H. (2011). An extension of the extended parallel process model (EPPM) in television health news: The influence of health consciousness on individual message processing and acceptance. Health communication, 26(4), 343-353.

IDC. (2014). Despite a Strong 2013, Worldwide Smartphone Growth Expected to Slow to Single Digits by 2017, According to IDC. Retrieved from http://www.idc.com/getdoc.jsp?containerId=prUS24701614

IDC. (2015). Worldwide Wearables Market Forecast to Reach 45.7 Million Units Shipped in 2015 and 126.1 Million Units in 2019. Retrieved from http://www.idc.com/getdoc.jsp?containerId=prUS25519615

Iversen, A. C., \& Kraft, P. (2006). Does socio-economic status and health consciousness influence how women respond to health related messages in media? Health Education Research, 21(5), 601-610. doi:10.1093/her/cyl014 
Jarvis, C. B., MacKenzie, S. B., \& Podsakoff, P. M. (2003). A critical review of construct indicators and measurement model misspecification in marketing and consumer research. Journal of Consumer Research, 30(2), 199-218.

Jayanti, R. K., \& Burns, A. C. (1998). The antecedents of preventive health care behavior: An empirical study. Journal of the Academy of Marketing Science, 26(1), 6.

Johnston, A. C., \& Warkentin, M. (2010). Fear appeals and information security behaviors: an empirical study. Mis Quarterly, 549-566.

Kaminska, O., McCutcheon, A. L., \& Billiet, J. (2010). Satisficing among reluctant respondents in a cross-national context. Public Opinion Quarterly, 74(5), 956-984.

Khechine, H., Lakhal, S., \& Ndjambou, P. (2016). A meta-analysis of the UTAUT model: Eleven years later. Canadian Journal of Administrative Sciences/Revue Canadienne des Sciences de l'Administration, 33(2), 138-152.

Kijsanayotin, B., Pannarunothai, S., \& Speedie, S. M. (2009). Factors influencing health information technology adoption in Thailand's community health centers: applying the UTAUT model. Int J Med Inform, 78(6), 404-416.

Kim, K. J., \& Shin, D.-H. (2015). An acceptance model for smart watches: implications for the adoption of future wearable technology. Internet Research, 25(4), 527-541.

Kim, S. (2009). The Integrative Framework of Technology Use: An Extension and Test. Mis Quarterly, 33(3), 513-537.

King, N. (2006). Using Interviews in Qualitative Research. In C. Cassell \& G. Symon (Eds.), Essential Guide to Qualitative Methods in Organizational Research (pp. 11-22). London ; Thousand Oaks: SAGE Publications.

Kobsa, A., Cho, H., \& Knijnenburg, B. P. (2016). The effect of personalization provider characteristics on privacy attitudes and behaviors: An Elaboration Likelihood Model approach. Journal of the Association for Information Science and Technology.

Komiak, S. Y. X., \& Benbasat, I. (2006). The Effects of Personalization and Familiarity on Trust and Adoption of Recommendation Agents. Mis Quarterly, 30(4), 941.

Kraft, F. B., \& Goodell, P. W. (1993). Identifying the health conscious consumer. Marketing Health Services, 13(3), 18.

Kuhn, T. (1996). The Structure of Scientific Revolutions (3rd ed). Chicago: University of Chicago Press.

Lai, I. K. W. (2015). Traveler Acceptance of an App-Based Mobile Tour Guide. Journal of Hospitality \& Tourism Research, 39(3), 401-432. doi:10.1177/1096348013491596

Lankton, N. K., Wilson, E. V., \& Mao, E. (2010). Antecedents and determinants of information technology habit. Information \& Management, 47(5), 300-307.

Ledger, D., \& McCaffrey, D. (2014). Inside wearables: How the science of Human Behaviour change. Retrieved from Endeavour Partners:

Leedy, P., \& Ormrod, J. (2001). Practical research: Planning and design New Jersey: Merril Prentice Hall.

Lewandowski, J., Chao, K.-M., \& Niżański, W. (2016). Design Concepts and Operation Principles for Smart Intra-Vaginal Health Monitoring Devices. Paper presented at the eBusiness Engineering (ICEBE), 2016 IEEE 13th International Conference on.

Lewis, C. C., Fretwell, C. E., Ryan, J., \& Parham, J. B. (2013). Faculty Use of Established and Emerging Technologies in Higher Education: A Unified Theory of Acceptance and Use of Technology Perspective. International Journal of Higher Education, 2(2), 22-34. 
Lewy, H. (2015). Wearable technologies-future challenges for implementation in healthcare services. Healthcare technology letters, 2(1), 2-5.

Li, H., Wu, J., Gao, Y., \& Shi, Y. (2016). Examining individuals' adoption of healthcare wearable devices: An empirical study from privacy calculus perspective. International Journal of Medical Informatics, 88, 8-17.

Liang, H., Saraf, N., Hu, Q., \& Xue, Y. (2007). Assimilation of enterprise systems: The effect of institutional pressures and the mediating role of top management. MIS Quarterly: Management Information Systems, 31(1), 59-87.

Liang, H., Xue, Y., Ke, W., \& Wei, K. K. (2010). Understanding the Influence of Team Climate on IT Use. Journal of the Association for Information Systems, 11(8), 414.

Lieberman, M. D. (2013). Social: Why our brains are wired to connect: OUP Oxford.

Limayem, M., Hirt, S. G., \& Cheung, C. M. K. (2007). How habit limits the predictive power of intention: The case of information systems continuance. Mis Quarterly, 31(4), 705-737.

Liu, D., \& Guo, X. (2016). Can Trust and Social Benefit Really Help? Empirical examination of purchase intentions for wearable devices. Information Development, 0266666916635724.

Locke, E. A., \& Latham, G. P. (2002). Building a practically useful theory of goal setting and task motivation: A 35-year odyssey. American Psychologist, 57(9), 705.

Lu, J., Yu, C.-S., Liu, C., \& Yao, J. E. (2003). Technology acceptance model for wireless Internet. Internet Research, 13(3), 206-222.

Luarn, P., \& Lin, H.-H. (2005). Toward an understanding of the behavioral intention to use mobile banking. Computers in Human Behavior, 21(6), 873-891.

Maddox, T. (2014). The scary truth about data security with wearables Retrieved from http://www.techrepublic.com/article/the-scary-truth-about-data-security-with-wearables/

Mai, R., \& Hoffmann, S. (2012). Taste lovers versus nutrition fact seekers: how health consciousness and self-efficacy determine the way consumers choose food products. Journal of Consumer Behaviour, 11(4), 316-328.

MäNtymäKi, M., \& Salo, J. (2011). Teenagers in social virtual worlds: Continuous use and purchasing behavior in Habbo Hotel. Computers in Human Behavior, 27(6), 2088-2097.

Mao, E., \& Zhang, J. (2013). The Role of Privacy in the Adoption of Location-Based Services. Journal of Information Privacy and Security, 9(2), 40-59. doi:10.1080/15536548.2013.10845678

Maxwell, J. A. (2012). Qualitative research design: An interactive approach (Vol. 41): Sage publications.

Meng, F., Guo, X., Peng, Z., Lai, K.-h., \& Vogel, D. (2016). Routine Use of Mobile Health Services in the Presence of Health Consciousness.

Michaelidou, N., \& Hassan, L. M. (2008). The role of health consciousness, food safety concern and ethical identity on attitudes and intentions towards organic food. International Journal of Consumer Studies, 32(2), 163-170.

Morgan, D. L. (2007). Paradigms Lost and Pragmatism Regained: Methodological Implications of Combining Qualitative and Quantitative Methods. Journal of Mixed Methods Research, 1(1), 48-76. doi:10.1177/2345678906292462

Morosan, C., \& DeFranco, A. (2016). It's about time: Revisiting UTAUT2 to examine consumers' intentions to use NFC mobile payments in hotels. International Journal of Hospitality Management, 53, 17-29. 
Mozos, O. M., Sandulescu, V., Andrews, S., Ellis, D., Bellotto, N., Dobrescu, R., \& Ferrandez, J. M. (2017). Stress detection using wearable physiological and sociometric sensors. International Journal of Neural Systems, 27(02), 1650041.

Neal, D. J., \& Carey, K. B. (2004). Developing discrepancy within self-regulation theory: Use of personalized normative feedback and personal strivings with heavy-drinking college students. Addictive Behaviors, 29(2), 281-297.

Nielsen. (2014a). Smarpthone Penetration Rate by Age Group, in Q2. Retrieved from http://www.marketingcharts.com/online/smartphone-penetration-rate-by-age-group-inq2-45774/

Nielsen. (2014b). Tech-Styles: Are Consumers Really Interested In Wearing Tech On Their Sleeves? Retrieved from http://www.nielsen.com/us/en/insights/news/2014/tech-stylesare-consumers-really-interested-in-wearing-tech-on-their-sleeves.html

Norberg, P. A., Horne, D. R., \& Horne, D. A. (2007). The privacy paradox: Personal information disclosure intentions versus behaviors. Journal of Consumer Affairs, 41(1), 100-126.

NPR. (2015). As Health Apps Hop On The Apple Watch, Privacy Will Be Key. Retrieved from http://www.npr.org/sections/alltechconsidered/2015/04/25/402039156/as-health-appshop-on-the-apple-watch-privacy-will-be-key

O'kane, M. J., Bunting, B., Copeland, M., \& Coates, V. E. (2008). Efficacy of self monitoring of blood glucose in patients with newly diagnosed type 2 diabetes (ESMON study): randomised controlled trial. $b m j, 336(7654), 1174-1177$.

Oechslein, O., Fleischmann, M., \& Hess, T. (2014). An application of UTAUT2 on social recommender systems: Incorporating social information for performance expectancy. Paper presented at the System Sciences (HICSS), 2014 47th Hawaii International Conference on.

Oliver, R. L. (1999). Whence consumer loyalty? Journal of Marketing, 33-44.

Park, J.-H. (2014). The effects of personalization on user continuance in social networking sites. Information Processing \& Management, 50(3), 462-475.

Pavlou, P. A., \& Fygenson, M. (2006). Understanding And Prediction Electronic Commerce Adoption: An Extension Of The Theory Of Planned Behavior. Mis Quarterly, 30(1), 115143.

Pfeiffer, J., von Entress-Fuersteneck, M., Urbach, N., \& Buchwald, A. (2016). Quantify-Me: Consumer Acceptance of Wearable Self-Tracking Devices. Paper presented at the Twenty-Fourth European Conference on Information Systems (ECIS), İstanbul,Turkey.

Piwek, L., Ellis, D. A., Andrews, S., \& Joinson, A. (2016). The rise of consumer health wearables: promises and barriers. PLoS Med, 13(2), e1001953.

Prince, J. D. (2014). The quantified self: Operationalizing the quotidien. Journal of Electronic Resources in Medical Libraries, 11(2), 91-99.

PwC. (2014). The wearable future. Consumer Intelligence Series. Retrieved from https://www.pwc.se/sv/media/assets/consumer-intelligence-series-the-wearablefuture.pdf

Qualtrics. (2017). Panel Management. Retrieved from http://www.qualtrics.com/panelmanagement/

Quantified-Self. (2017). Quantified Self. Self knowledge thourgh numbers. Retrieved from http://quantifiedself.com/ 
Rayner, S. (2011). Researching style: Epistemology, paradigm shifts and research interest groups. Learning and Individual Differences, 21(3), 255-262. doi:10.1016/j.lindif.2010.11.020

Rhee, K. S. (2008). The beat and rhythm of competency development over two years. The Journal of Management Development, 27(1), 146.

Rigdon, E. E., Becker, J.-M., Rai, A., Ringle, C. M., Diamantopoulos, A., Karahanna, E., . . . Dijkstra, T. K. (2014). Conflating antecedents and formative indicators: A comment on Aguirre-Urreta and Marakas. Information Systems Research, 25(4), 780-784.

Ringle, C. M., Wende, S., \& Becker, J.-M. (2015). SmartPLS3. Bönningstedt: SmartPLS. Retrieved from http://www.smartpls.com/

Rodrigues, G., Sarabdeen, J., \& Balasubramanian, S. (2016). Factors that Influence Consumer Adoption of E-government Services in the UAE: A UTAUT Model Perspective. Journal of Internet Commerce, 15(1), 18-39. doi:10.1080/15332861.2015.1121460

Salah, H., MacIntosh, E., \& Rajakulendran, N (2014). Wearable Tech: Leveraging Canadian Innovation to Improve Health. Retrieved from http://www.marsdd.com/newsinsights/mars-reports/

Salo, J., \& Karjaluoto, H. (2007). A conceptual model of trust in the online environment. Online Information Review, 31(5), 604-621. doi:10.1108/14684520710832324

Santos, J. R. A. (1999). Cronbach's Alpha: A Tool for Assessing the Reliability of Scales. Journal of Extension, 37(2).

Segar, M. L., Eccles, J. S., \& Richardson, C. R. (2011). Rebranding exercise: closing the gap between values and behavior. International journal of behavioral nutrition and physical activity, 8(1), 94.

Sergueeva, K., \& Shaw, N. (2016, July). Wearable technology in hospitals: Overcoming patients' concerns. Paper presented at the 18th International Conference on HumanComputer Interaction, Toronto, Canada.

Shaw, N. (2015). The Mediating Role of Perceived Security: an Empirical Study of Mobile Wallet Adoption in USA. Paper presented at the 17th International Conference on HumanComputer Interaction, Los Angeles, 5 to 7 August 2015.

Sheehan, K. B., \& Hoy, M. G. (2000). Dimensions of Privacy Concern among Online Consumers. Journal of Public Policy \& Marketing, 19(1), 62-73. doi:10.1509/jppm.19.1.62.16949

Sheng, Q. Z., Li, X., \& Zeadally, S. (2008). Enabling next-generation RFID applications: Solutions and challenges. Computer, 41(9), 21.

Shull, P. B., Jirattigalachote, W., Hunt, M. A., Cutkosky, M. R., \& Delp, S. L. (2014). Quantified self and human movement: a review on the clinical impact of wearable sensing and feedback for gait analysis and intervention. Gait \& posture, 40(1), 11-19.

Slade, E. L., Williams, M. D., \& Dwivedi, Y. K. (2014). Devising a research model to examine adoption of mobile payments: An extension of UTAUT2. The Marketing Review, 14(3), 310-335.

Statista. (2017). Number of smartphone users in the United States from 2010 to 2021 (in millions)*. Retrieved from https://www.statista.com/statistics/201182/forecast-ofsmartphone-users-in-the-us/

Statista. (n.d.). Smartwatch unit sales worldwide from 2014 to 2018 (in millions). https://www.statista.com/statistics/538237/global-smartwatch-unit-sales/ 
Sultan, N. (2015). Reflective thoughts on the potential and challenges of wearable technology for healthcare provision and medical education. International Journal of Information Management, 35(5), 521-526. doi:10.1016/j.ijinfomgt.2015.04.010

Sun, Y., Wang, N., Guo, X., \& Peng, Z. (2013). Understanding The Acceptance Of Mobile Health Services: A Comparison And Integration Of Alternative Models. Journal of Electronic Commerce Research, 14(2).

Sutanto, J., Palme, E., Tan, C.-H., \& Phang, C. W. (2013). Addressing the personalizationprivacy paradox: an empirical assessment from a field experiment on smartphone users. Mis Quarterly, 37(4), 1141-1164.

Swan, M. (2009). Emerging patient-driven health care models: an examination of health social networks, consumer personalized medicine and quantified self-tracking. International journal of environmental research and public health, 6(2), 492-525. doi:10.3390/ijerph6020492

Tai, S. H. C., \& Tam, J. L. M. (1997). A Lifestyle Analysis of Female Consumers in Greater China: ABSTRACT. Psychology \& Marketing (1986-1998), 14(3), 287.

Taylor, S., \& Todd, P. A. (1995a). Assessing IT usage: The role of prior experience. Mis Quarterly, 19(4), 561-570.

Taylor, S., \& Todd, P. A. (1995b). Understanding Information Technology Usage: A Test of Competing Models. Information Systems Research, 6(2), 144-176.

Teh, P.-L., K., A. P., Cheong, S.-N., \& Yap, W.-J. (2014). Age-group differences in Near Field Communication smartphone. Industrial Management \& Data Systems, 114(3), 484-502. doi:10.1108/IMDS-06-2013-0274

Tehrani, K., \& Michael, A. . (2014, March). Wearable Technology and wearable devices: Everything you need to know. Wearable Devices Magazine.

Thompson, R. L., Higgins, C. A., \& Howell, J. M. (1991). Personal Computing: Toward a Conceptual Model of Utilization. Mis Quarterly, 15(1), 125.

Toch, E., Wang, Y., \& Cranor, L. F. (2012). Personalization and privacy: a survey of privacy risks and remedies in personalization-based systems. User Modeling and User-Adapted Interaction, 22(1-2), 203-220.

Trimmer, K., Cellucci, L. W., Wiggins, C., \& Woodhouse, W. (2009). Electronic medical records: TAM, UTAUT, and culture. International Journal of Healthcare Information Systems and Informatics (IJHISI), 4(3), 55-68.

Vallerand, R. J. (1997). Toward a hierarchical model of intrinsic and extrinsic motivation. Advances in experimental social psychology, 29, 271-360.

Van den Bulck, J. (2015). Sleep apps and the quantified self: blessing or curse? Journal of sleep research, 24(2), 121-123.

Varshney, U. (2014). Mobile health: Four emerging themes of research. Decision Support Systems, 66, 20-35.

Venkatesh, V. (2014). Technology Acceptance Model And The Unified Theory Of Acceptance And Use Of Technology. Wiley Encyclopedia of Management.

Venkatesh, V., \& Davis, F. D. (2000). A theoretical extension of the technology acceptance model: Four longitudinal field studies. Management Science, 46(2), 186-204.

Venkatesh, V., \& Morris, M. G. (2000). Why don't men ever stop to ask for dirrections? Gender, social influence, and their role in technology acceptance and usage behavior. Mis Quarterly, 24(1), 115. 
Venkatesh, V., Morris, M. G., Davis, G. B., \& Davis, F. D. (2003). User acceptance of information technology: Toward a unified view1. Mis Quarterly, 27(3), 425-278.

Venkatesh, V., Thong, J., \& Xu, X. (2012). Consumer Acceptance and Use of Information Technology: Extending the Unified Theory of Acceptance and Use of Technology. Mis Quarterly, 36(1), 157-178.

Venkatesh, V., \& Zhang, X. (2010). Unified Theory of Acceptance and Use of Technology: U.S. Vs. China. Journal of Global Information Technology Management, 13(1), 5-27. doi:10.1080/1097198X.2010.10856507

Wang, T., Jung, C.-H., Kang, M.-H., \& Chung, Y.-S. (2014). Exploring determinants of adoption intentions towards Enterprise 2.0 applications: an empirical study. Behaviour \& Information Technology, 33(10), 1048-1064.

Wang, Y., Millet, B., \& Smith, J. L. (2016). Designing wearable vibrotactile notifications for information communication. International Journal of Human-Computer Studies, 89, 2434.

Wong, C.-H., Wei-Han Tan, G., Loke, S.-P., \& Ooi, K.-B. (2014). Mobile TV: a new form of entertainment? Industrial Management \& Data Systems, 114(7), 1050-1067. doi:10.1108/IMDS-05-2014-0146

Wu, Sum, K., \& Nathan-Roberts, D. (2016). How Fitness Trackers Facilitate Health Behavior Change. Paper presented at the Proceedings of the Human Factors and Ergonomics Society Annual Meeting.

Wu, L. H., Wu, L. C., \& Chang, S. (2016). Exploring consumers' intention to accept smartwatch. Computers in Human Behavior, 64, 383-392.

Wu, P. F. (2012). A Mixed Methods Approach to Technology Acceptance Research. Journal of the Association for Information Systems, 13(3).

Xiao, N., Sharman, R., Rao, H. R., \& Upadhyaya, S. (2014). Factors influencing online health information search: An empirical analysis of a national cancer-related survey. Decision Support Systems, 57, 417. doi:10.1016/j.dss.2012.10.047

Xu, Gupta, S., \& Pan, S. (2009). Balancing user privacy concerns in the adoption of locationbased services: an empirical analysis across pull-based and push-based applications.

Xu, Luo, X., Carroll, J. M., \& Rosson, M. B. (2011). The personalization privacy paradox: An exploratory study of decision making process for location-aware marketing. Decision Support Systems, 51(1), 42-52. doi:10.1016/j.dss.2010.11.017

Xu, H., Teo, H.-H., Bernard, C. Y. T., \& Agarwal, R. (2012). Effects of Individual SelfProtection, Industry Self-Regulation, and Government Regulation on Privacy Concerns: A Study of Location-Based Services. Information Systems Research, 23(4), 1342.

$\mathrm{Xu}$, J., Benbasat, I., \& Cenfetelli, R. T. (2014). Research Note-The Influences of Online Service Technologies and Task Complexity on Efficiency and Personalization. Information Systems Research.

Xu, J., \& Quaddus, M. (2007). Exploring the Factors Influencing End Users' Acceptance of Knowledge Management Systems: Development of a Research Model of Adoption and Continued Use. Journal of Organizational and End User Computing, 19(4), 57.

Yang, H., Yu, J., Zo, H., \& Choi, M. (2016). User acceptance of wearable devices: An extended perspective of perceived value. Telematics and Informatics, 33(2), 256-269.

Yang, S. (2013). Understanding undergraduate students' adoption of mobile learning model: a perspective of the extended UTAUT2. Journal of convergence information technology, 8(10), 969-979. 
Yoshikawa, H., Weisner, T. S., Kalil, A., \& Way, N. (2013). Mixing qualitative and quantitative research in developmental science: Uses and methodological choices. Paper presented at the Mixed Methods Research on Economic Conditions, Public Policy, and Child and Family Well-Being, Jun, 2005, US; This article was partially based on the aformentioned conference, which was sponsored by the National Poverty Center, University of Michigan. Additional support for that conference was provided by the American Psychological Association and the National Institute of Child Health and Human Development to Ariel Kalil and Hirokazu Yoshikawa.

Zhou, T. (2011). An empirical examination of initial trust in mobile banking. Internet Research, $21(5), 2-2$.

Zhou, T. (2012). Examining Location-Based Services Usage From The Perspectives Of Unified Theory Of Acceptance And Use Of Technology And Privacy Risk. Journal of Electronic Commerce Research, 13(2). 